\title{
A Mechanistic Review of $\beta$-Carotene, Lutein, and Zeaxanthin in Eye Health and Disease
}

\author{
Fatima Tuj Johra, Asim Kumar Bepari $\mathbb{D}$, Anika Tabassum Bristy and Hasan Mahmud Reza * \\ Department of Pharmaceutical Sciences, School of Health and Life Sciences, North South University, \\ Bashundhara R/A, Dhaka 1229, Bangladesh; fatima.johra@northsouth.edu (F.T.J.); \\ asim.bepari@northsouth.edu (A.K.B.); anika.bristy@northsouth.edu (A.T.B.) \\ * Correspondence: hasan.reza@northsouth.edu; Tel.: +880-255668200 (ext. 1954)
}

Received: 12 September 2020; Accepted: 22 October 2020; Published: 26 October 2020

check for updates

\begin{abstract}
Carotenoids are natural lipid-soluble antioxidants abundantly found as colorful pigments in fruits and vegetables. At least 600 carotenoids occur naturally, although about 20 of them, including $\beta$-carotene, $\alpha$-carotene, lycopene, lutein, zeaxanthin, meso-zeaxanthin, and cryptoxanthin, are detectable in the human blood. They have distinct physiological and pathophysiological functions ranging from fetal development to adult homeostasis. $\beta$-carotene is a precursor of vitamin $A$ that essentially functions in many biological processes including vision. The human macula lutea and eye lens are rich in lutein, zeaxanthin, and meso-zeaxanthin, collectively known as macular xanthophylls, which help maintain eye health and prevent ophthalmic diseases. Ocular carotenoids absorb light from the visible region (400-500 $\mathrm{nm}$ wavelength), enabling them to protect the retina and lens from potential photochemical damage induced by light exposure. These natural antioxidants also aid in quenching free radicals produced by complex physiological reactions and, consequently, protect the eye from oxidative stress, apoptosis, mitochondrial dysfunction, and inflammation. This review discusses the protective mechanisms of macular xanthophylls in preventing eye diseases such as cataract, age-related macular degeneration, and diabetic retinopathy. Moreover, some preclinical animal studies and some clinical trials are discussed briefly to understand carotenoid safety and efficacy.
\end{abstract}

Keywords: carotenoids; xanthophylls; eye disease; cataract; age-related macular degeneration; diabetic retinopathy; oxidative stress; zeaxanthin; lutein; $\beta$-carotene

\section{Introduction}

The major causes of progressive and irreversible loss of vision include various ophthalmic diseases such as cataract, age-related macular degeneration (AMD), glaucoma, and diabetic retinopathy. Initiation and progression of these disorders involve oxidative stress, apoptosis, mitochondrial dysfunction, and inflammation [1,2]. For instance, increased oxidative stress of retinal cells damages the mitochondrial DNA in diabetic retinopathy, one of the most deleterious eye-related complications of diabetes [3]. Oxidative stress is also a significant contributor to the pathophysiology of age-related cataract, a leading cause of blindness globally [2,4]. A growing body of evidence indicates that dietary antioxidants can prevent and treat many ophthalmic disorders associated with oxidative stress. Lutein, zeaxanthin, and meso-zeaxanthin (synthesized from lutein in the retina) are dipolar, terminally dihydroxylated carotenoids, also known as macular xanthophylls, and are obtained from dietary sources [5,6]. Macula lutea of the eye, also known as the yellow spot, contains high concentrations of macular xanthophylls. The peak concentrations of lutein and zeaxanthin appear at the center of the fovea [7]. Lutein and zeaxanthin are also found in the lens; however, $\beta$-carotene and lycopene have not been detected [8]. 
Carotenoids are the most abundant pigment groups and lipid-soluble antioxidants in nature that are responsible for the yellow, orange, or red color of fruits, leaves, and flowers $[9,10]$. They are C40-based isoprenoids of the tetraterpene family and are biosynthesized by the linkage of two C20 geranylgeranyl diphosphate molecules [11,12]. Stahl and Sies (2005) divided carotenoids into two classes: pro-vitamin A (e.g., $\beta$-carotene, $\alpha$-carotene, and $\beta$-cryptoxanthin) and non-pro-vitamin A compounds [13]. Later, Jomova and Valko (2013) classified 600 naturally occurring carotenoids into three groups: carotenes, xanthophylls, and lycopene [14]. $\beta$-carotene, $\alpha$-carotene, lycopene, lutein, and cryptoxanthin are some dietary carotenoids found in human blood [15]. $\beta$-carotenes, which are precursors of vitamin A, have greater pro-vitamin A potential compared to $\alpha$-carotene or $\beta$-cryptoxanthin because of the presence of a $\beta$-ionone ring linked to a chain of 11 carbons $[10,16]$. $\beta$-carotene, $\alpha$-carotene, and lycopene are composed only of carbon and hydrogen atoms, whereas xanthophylls are carotenoids with at least one oxygen atom. Zeaxanthin, lutein, $\alpha$-and $\beta$-cryptoxanthin, canthaxanthin, and astaxanthin are important xanthophylls containing hydroxy and keto groups in their structures [13]. The presence of conjugated double bonds in the structure enables carotenoids to accept electrons from reactive species, neutralize free radicals, and isomerize and help in oxidation in the presence of oxygen, light, and heat [17]. Chemical reactivity, distinctive shape, and light-absorbing properties of carotenoids are attributed to the alternating double and single bonds present in the nucleus of a polyene chain that constitute a conjugated system with delocalized $\pi$-electrons. Different structural configurations and shapes exist because of the isomerism around $\mathrm{C}=\mathrm{C}$ double bonds (e.g., trans or cis isomer) and possible rotation around $\mathrm{C}-\mathrm{C}$ single bonds in the polyene chain. Compared to the trans isomers, cis isomers exhibit a higher structural instability owing to the steric hindrance between either hydrogen or methyl groups. Free rotation between the C- 6 and C-7 single bonds in carotenoids allows them to twist and form an infinite number of possible angles between the ring structure and the main polyene chain. Carotenoids absorb light from the visible region in the wavelength range of $400-500 \mathrm{~nm}$, promoting one of the $\pi$-electrons of the conjugated double to the previously unoccupied $\pi^{*}$ antibonding orbital [18]. Epidemiological studies identified the association of high dietary carotenoid intake with reduced risks of breast, cervical, ovarian, colorectal, cardiovascular, and eye diseases [19]. The U.S. Department of Agriculture reported that the average daily intake of lutein by Americans is about $1.7 \mathrm{mg}$ per day, and in Europe, it is $2.3 \mathrm{mg}$ per day. However, these values are far below the recommended dietary intake level of 6 to $14 \mathrm{mg}$ per day to reduce the risk of macular degeneration and cataract [20].

\section{Age-Related Macular Degeneration (AMD)}

The amount of macular pigment is inversely associated with the incidence of AMD. Macular pigment levels can be improved by increasing the intake of foods rich in lutein and zeaxanthin (e.g., dark-green leafy vegetables) and supplementation. Lutein and zeaxanthin have been proved to be protective against the development of AMD in many studies [21,22].

The retina of the human eye is abundantly supplied with oxygen. Prolonged or repeated exposure of light decreases long-chain polyunsaturated fatty acids in the retina, increases lipid conjugated dienes, and causes selective degeneration of photoreceptors and retinal damage [23]. Exposure of blue light in the retina is known to cause oxidative stress, mitochondrial and inflammatory apoptosis, and DNA damage; all of these lead to the development of glaucoma, keratitis, $\mathrm{H}$ and dry eye disease. [24]. Exposure of UV and visible light causes simultaneous photochemical isomerization of retinal chromophores and activation of photoreceptors (e.g., rhodopsin, melanin, lipofuscin, etc.) coupled with the chromophores. These events produce an electronic transition to the excited state and change chromophore structures from the 11-cis to the all-trans forms [25], and the retina undergoes a significant conformational change upon light absorption [26]. Reactive oxygen species (ROS) such as, free radicals, hydrogen peroxide, and singlet oxygen, generated by oxidative stress, cause cellular damage, promote the aging process in retina, and eventually lead to progression of AMD. For quenching these ROS and protecting retina from AMD, a particular transmembrane orientation of 
macular xanthophylls has been proposed [5]. Macular xanthophylls located transversely in the lipid bi-layer of the retinal membrane are able to prevent AMD and protect the retina against peroxidation and photo-damage by acting as antioxidants that quench free radicals and ROS [5]. They also prevent blue light exposure to fovea's photoreceptors significantly [25] (Figure 1).

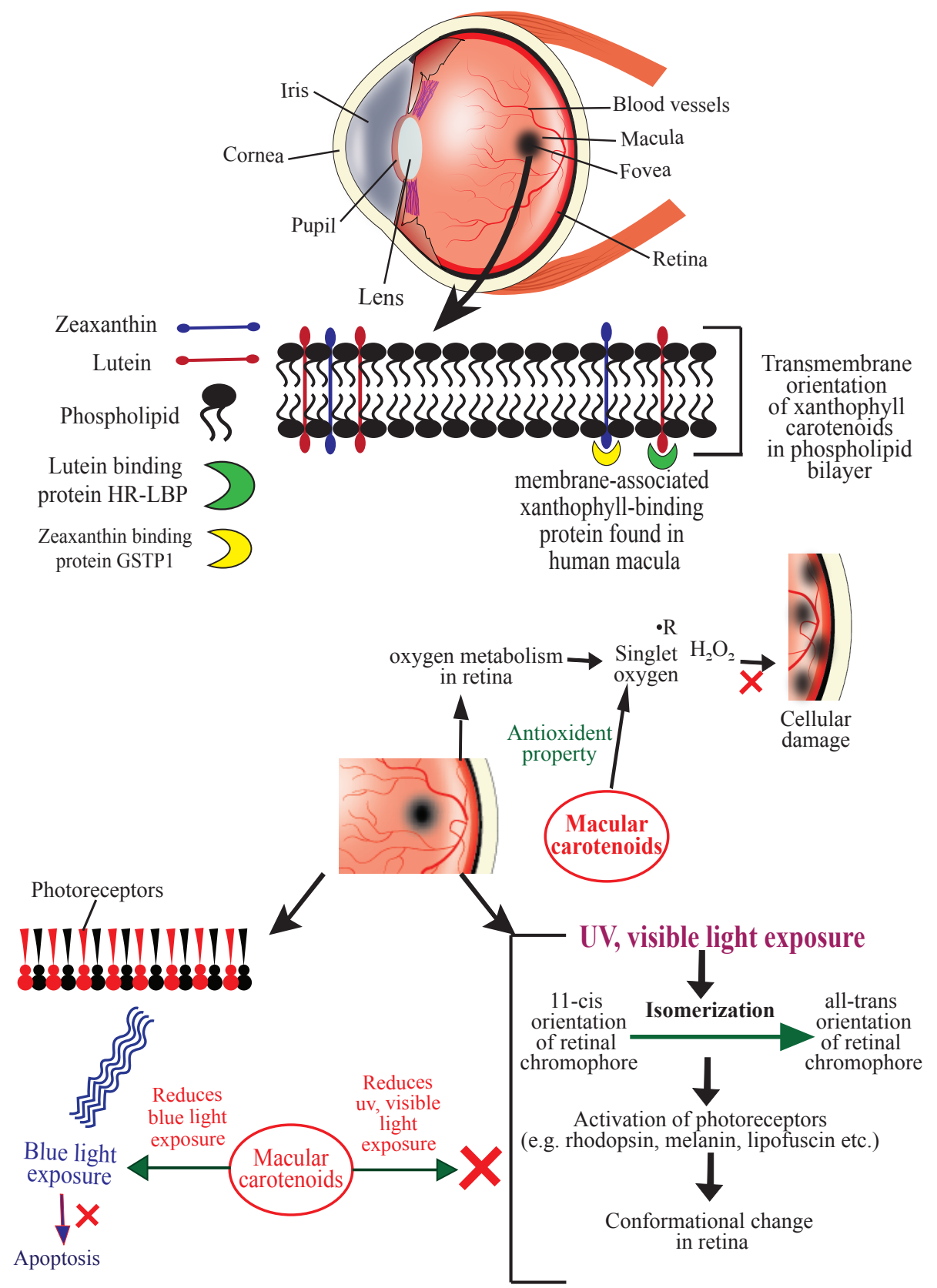

Figure 1. Schematic diagram showing the mechanisms of action of carotenoids to prevent age-related macular degeneration (AMD). HR-LBP: human retinal lutein-binding protein; GSTP1: glutathione S-transferase Pi 1; R: free radical (symbolic representation).

Bhosale et al. (2004) isolated and purified a membrane-associated xanthophyll-binding protein from human macula using ion-exchange chromatography and gel-exclusion chromatography. This protein is a Pi isoform of human glutathione S-transferase (GSTP1) to which zeaxanthin displayed the highest affinity. Uptake, metabolism, and stabilization of zeaxanthin in the retina were found to be mediated by this xanthophyll-binding protein [27]. The HR-LBP, a membrane-associated human retinal lutein-binding protein, displayed a saturable and specific binding toward lutein [28]. 
Once incorporated in the lipid bilayer, macular xanthophylls help quench singlet oxygen and other free radicals and thus prevent lipid peroxidation in the retina [29-33]. Carotenoids also protect against oxidative damage by repairing $\alpha$-tocopherol and acting synergistically with vitamin $C$ [23]. Figure 1 illustrates the mechanisms of action of ocular carotenoids to prevent AMD.

\section{Cataracts}

A cataract is a visualization problem in which the lens develops opacity, and age-related cataract is a leading cause of blindness. Depending on the morphology, cataract is classified into different types. The outer section of the tissue becomes opaque in cortical cataracts, the inner core in nuclear cataracts, and the superficial region below the capsule on the posterior side in posterior subcapsular cataracts [34]. In western countries, cataract surgery is most frequently done in people aged 65 years or older [35]. This is one of the most common surgical procedures among the general population, and the prevalence is increasing each year [36]. In the United States, 3.38 million cataract surgeries were performed in 2017 [37]. Although cataract is mainly an age-related phenomenon, socioeconomic and lifestyle factors (smoking, diet, intake of nutrients, alcohol consumption, etc.) also influence cataract initiation and progression $[35,38]$.

The main constituents of an eye lens are crystallins (90\%), and cytoskeletal and membrane proteins. Crystallins have a high refractive index and form a complex protein solution in the cytoplasm of lens fibers, conferring transparency. With age, this protein slowly leaves the soluble phase. Subsequently, disulfide bond formation and non-enzymatic glycation alter attractive forces between lens proteins [34] (Figure 2). Masters et al. (1977) observed aspartic acid racemization during aging and cataract formation on a D/L enantiomeric analysis of control human lenses and cataracts [39]. The insoluble fraction of D-aspartic acid becomes less abundant in cataractous lenses [40]. Thus, crystallins may undergo various post-translational modifications such as oxidation, glycation, proteolysis, transamidation, carbamylation, and phosphorylation [41]. These changes result in aggregation of proteins, disruption of healthy lens cell structure, and opacification.

Ocular oxidative stress may result from an imbalance between the generation of reactive oxygen species (ROS) and the cellular antioxidant defense mechanisms and subsequently initiate lens opacification [42]. ROS, such as hydrogen peroxide, superoxide, and hydroxyl radicals, negatively modifies the lens, whereas antioxidants, including glutathione (GSH), ascorbate, and catalase, rescue the lens proteins against ROS $[43,44]$. Hydrogen peroxide, the primary oxidant in the pathogenesis of cataract, is eliminated by catalase and glutathione through enzymatic reactions. A decreased level of reduced glutathione in older lenses' nucleus promotes cataract formation [43,45]. An imbalance in redox reactions can also initiate lipid peroxidation, promoting cataractogenesis. Spector (1995) mentioned that the massive oxidation of thiol to protein and mixed disulfides, cysteic acid, and methionine sulfoxide and cataract-extensive methionine sulfoxide formation are common in older lens [34]. In the nucleus of nuclear cataracts, covalently linked disulfide bonds containing polypeptides and in cortical cataracts, high molecular weight disulfide-linked aggregates were found [46]. Thus, oxidation of crucial sulfhydryl groups of enzymes and membrane proteins and the peroxidation of lenticular plasma membrane lipids also contribute to cataract pathogenesis [47].

Carotenoids' roles as antioxidants are known for many decades. $\beta$-carotene was found to markedly inhibit lipid peroxidation induced by xanthine oxidase in a pioneering study by Kellogg III and Fridovich [48]. Chemical antioxidants (e.g., $\alpha$-tocopherol, $\beta$-carotene, ascorbate, and GSH) and structural antioxidants (e.g., cholesterol and membrane protein) are implicated in preventing oxidative damage of the ocular tissues [49]. Christen (1994) reviewed antioxidants' protective effects in cataract and macular degeneration and found that animal studies invariably advocated in favor of dietary antioxidants, although results from epidemiological analyses were inconclusive [50]. The mechanisms of preventive functions of carotenoids in cataract formation are shown in Figure 2.

Human lens contains lutein and zeaxanthin but not $\beta$-carotene [51]. It has been suggested that antioxidants lutein and zeaxanthin are delivered continuously from the body pool to the 
epithelial/cortical layer of the lens, where they scavenge ROS by up-regulating GSH, catalase and SOD activities [52]. Gao et al. (2011) reported that lutein and zeaxanthin could reduce the risk for senile cataract by protecting lens protein, lipid, and DNA from oxidative damage. They incubated human lens epithelial cells with or without $5 \mu \mathrm{M}$ lutein, zeaxanthin, or $\alpha$-tocopherol for $48 \mathrm{~h}$. Then the cells were exposed to $100 \mu \mathrm{M} \mathrm{H}_{2} \mathrm{O}_{2}$ for $1 \mathrm{~h}$ to induce oxidative stress. By using a battery of in vitro analyses, the authors observed that the levels of $\mathrm{H}_{2} \mathrm{O}_{2}$-induced protein carbonyl, MDA, and DNA damage were significantly reduced by lutein and zeaxanthin [53]. Interestingly, cataract patients exhibited increased serum levels of pro-oxidants and decreased levels of antioxidants. Serum level of MDA was significantly higher, and levels of superoxide dismutase (SOD) and glutathione peroxidase (GPX) were substantially lower in age-related cataract patients compared to healthy volunteers $[54,55]$.

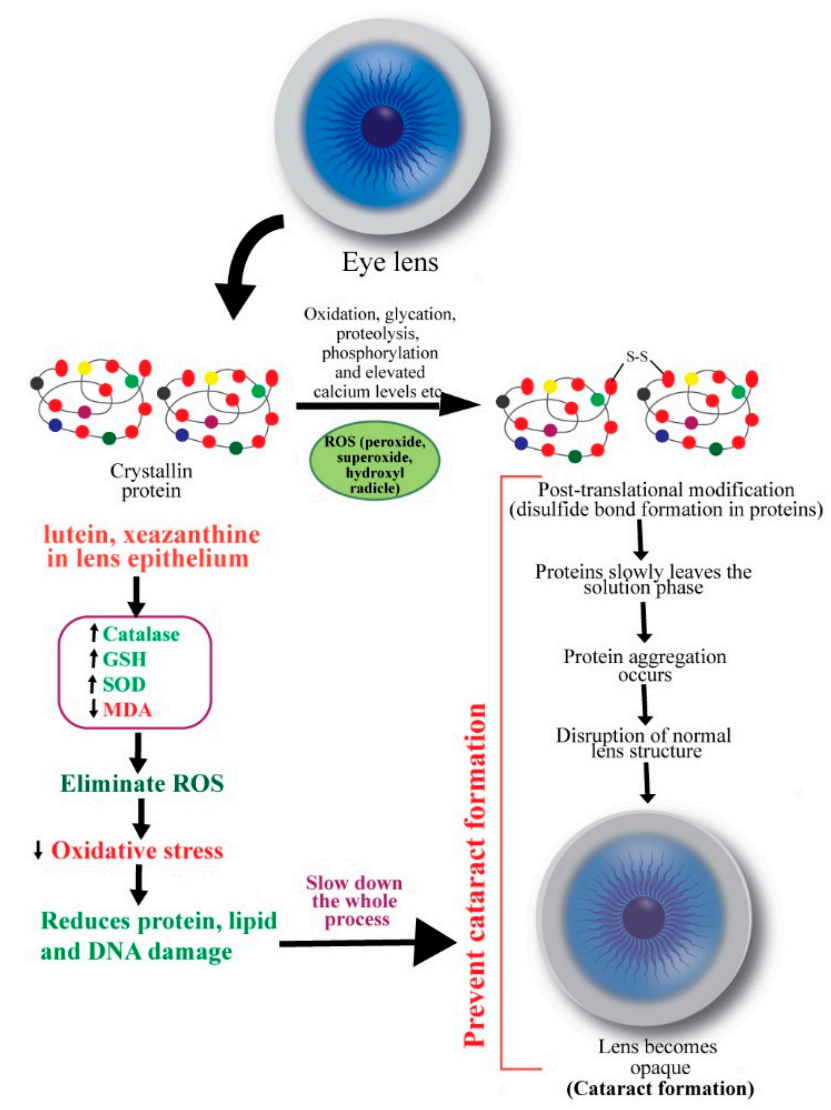

Figure 2. Schematic diagram showing the mechanisms of action of carotenoids to prevent cataract. ROS: reactive oxygen species.

\section{Diabetic Retinopathy}

Glycemic control, diabetes duration, hypertension, hyperlipidemia, smoking, age, and genetic factors are responsible for developing microvascular complications like diabetic retinopathy, diabetic nephropathy, and diabetic neuropathy [56]. Diabetic retinopathy is prevalent in people with Type 1 and Type 2 diabetes mellitus. Glycated hemoglobin (HbA1c), a measure of mean glycemia, has been identified as a risk factor for the progression of diabetic retinopathy $[57,58]$. Carotenoids enhance insulin sensitivity and have a protective effect against diabetes-related infectious diseases [59].

In diabetes, the high glucose level present in the microvasculature of the retina compromises the electron transport chain system, produces superoxides, damages mitochondrial DNA and decreases proteins encoded by its DNA, and thus, causes metabolic, structural, and functional changes in the retina [60]. Hyperglycemia can initiate many biochemical changes in the retinal microvasculature, including increased oxidative stress in the polyol pathway, protein kinase C (PKC) activation, and advanced glycation end-product formation [61] (Figure 3). Rat retinal endothelial cells exposed to 
high glucose (HG) showed a down-regulation of the protein kinase B (also known as AKT) pathway and increased apoptosis [62]. HG was also found to increase mitochondrial fragmentation and pro-apoptotic cytochrome c levels in vascular cells of rat retinal capillaries $[63,64]$. Increased oxidative stress, elevated oxidatively modified DNA, and up-regulated nitrosylated proteins ensue an impairment in antioxidant defense enzymes, which eventually leads to increased retinal capillary cell apoptosis [65]. Further, mitochondrial metabolism generates ROS, such as superoxides and hydrogen peroxide, that can damage proteins, lipids, and DNA. The damage of proteins can be compensated because of continuous biosynthesis; however, DNA damage can be devastating if a fixed mutation occurs. If reactive oxygen species damage a portion of a single DNA strand (e.g., the addition of 8-oxo-2'-hydroxyguanine in DNA strand) and DNA polymerases copy that damaged templates during replication, then, this error becomes permanent [66-68] (Figure 3).

DNA double-strand can also be affected and broken by free radicals. This breakdown is usually repaired by ligating nonhomologous DNA ends, an error-prone repair system [68]. In an in vitro study, Santos, Tewari and Kowluru, (2012) observed that the damage caused by ROS was compensated by increased mitochondrial DNA biosynthesis and repair system in the early stages of diabetes (15 days to 2 months). At a stable diabetic condition (at 6 months of diabetes) with constant production of high ROS, mitochondrial DNA and electron transport chain (ETC) were damaged because repair/replication machinery became subnormal and mitochondrial DNA copy number was significantly decreased. An increase in apoptosis was also observed in the above study [69]. Compromised DNA repair machinery, decreased gene expressions of mitochondrial-encoded proteins, and increased mtDNA damage were observed at high glucose exposure of retinal endothelial cells [70]. Aso et al. (2000) observed a higher amount of advanced glycation end-products (non-enzymatic binding of glucose to free amino groups of an amino acid) in patients with retinopathy [71,72]. In hyperglycemic conditions, a high glucose level causes overproduction of a glycolytic metabolite glyceraldehyde-3-phosphate. Glyceraldehyde-3-phosphate can easily be converted into 1, 3 Diphosphoglycerate by converting nicotinamide adenine dinucleotide (NAD+) into to its reduced form (NADH) when ROS inhibits the overproduction of glyceraldehyde-3-phosphate dehydrogenase (GADPH). NADH facilitates the protein kinase C (PKC) pathway and the AGE pathway [73]. Advanced glycation end-products (AGEs) (glucosepane and methylglyoxal hydroimidazolone) were significantly associated with the progression of retinopathy [74].

Antioxidants such as ascorbate, tocopherol, and carotenoids protect ocular oxidative damage [75]. Carotenoids can quench free radicals, scavenge reactive oxygen species, modulate gene expression, reduce inflammation, and prevent diabetes-related microvascular complications, including diabetic retinopathy, nephropathy, and neuropathy [76]. Macular pigment (MP), including lutein, zeaxanthin and mesozeaxanthin also contributes to the protection of the retinal tissue by conferring potent antioxidant and anti-inflammatory effects in diabetes. It has been demonstrated that patients with type 2 diabetes have a lower level of MP as compared to healthy controls [77]. Lutein supplementation is known to prevent oxidative damage in the retina [78]. In a mouse model of early diabetic retinopathy, long-term lutein administration attenuated inflammation, and vascular damage of the retina [79]. Intriguingly, short-term lutein treatment also down-regulated reactive oxygen species and up-regulated superoxide dismutase (SOD), attenuating inflammation and protecting the photo-stressed retina from oxidative damage [80]. Several signaling pathways, including PKC, vascular endothelial growth factor (VEGF), nuclear factor erythroid 2-related factor 2 (Nrf2), and Rho/Rho-associated coiled-coil containing protein kinase (Rho/ROCK), have been implicated in carotenoid-mediated protection of the retina in diabetic retinopathy [81]. An in vitro study showed that co-administration of lutein and zeaxanthin attenuated VEGF-induced oxidative stress in the retinal endothelium [82]. Lutein was found to modulate the SIRT1 signaling and inhibit premature senescence in retinal pigment epithelium cells [83]. Recent studies indicate that carotenoids could exert therapeutic benefits in diabetic retinopathy through multiple cellular and molecular pathways. The mechanisms of action of carotenoids to prevent diabetic retinopathy discussed above are sketched in Figure 3. 


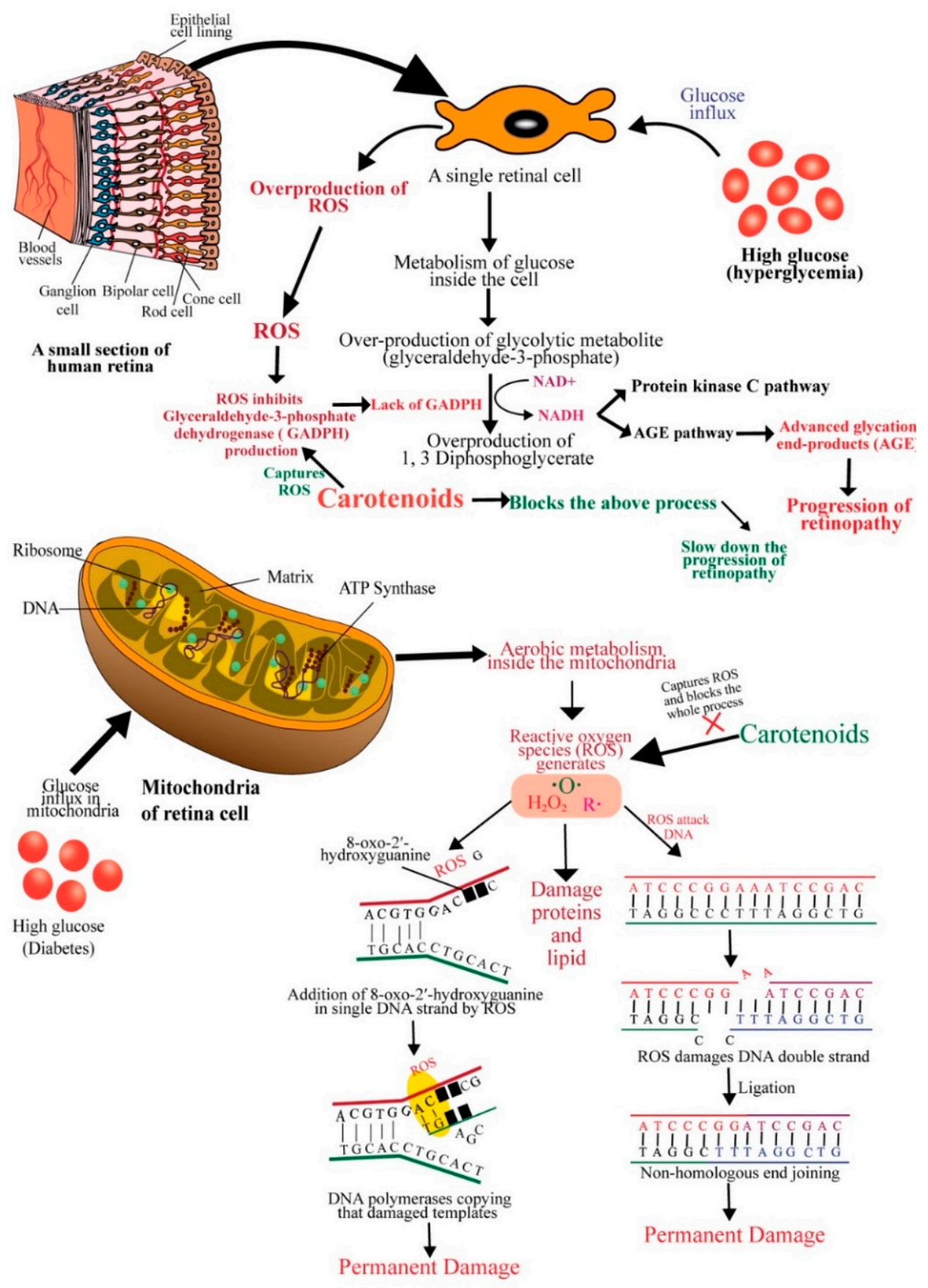

Figure 3. Schematic diagram showing the mechanisms of action of carotenoids to prevent diabetic retinopathy. ROS: reactive oxygen species; GADPH: glyceraldehyde-3-phosphate dehydrogenase; AGE: advanced glycation end-product; DNA: deoxyribonucleic acid; ATP: adenosine triphosphate.

\section{Safety of Carotenoids}

Several lines of evidence have demonstrated the safety profiles of carotenoids supplementation at different doses and duration in experimental animals. Table 1 summarizes some of these outcomes.

\section{Clinical Trials}

Clinical trials are the final step assessments of any drug before it is approved for regular human application. Twenty-six (26) important clinical trials are summarized in Table 2 to understand the efficacy of carotenoids as prophylactic and therapeutic uses in eye diseases. 
Table 1. In vivo preclinical studies to assess the safety of carotenoids.

\begin{tabular}{|c|c|c|c|c|c|}
\hline Reference & $\begin{array}{l}\text { Type and Number of } \\
\text { Animal Used }\end{array}$ & Duration of Therapy & $\begin{array}{l}\text { Name and Dose of } \\
\text { Carotenoids Administered }\end{array}$ & Parameters Observed & Findings and Observation \\
\hline$[84]$ & $\begin{array}{c}120 \text { wistar strain rats } \\
\text { (60 males and } 60 \text { females) }\end{array}$ & 90 days & $\begin{array}{l}\text { Lutein/zeaxanthin at the } \\
\text { concentrate of } 0,4,40, \\
\text { and } 400 \mathrm{mg} / \mathrm{kg} \text { body } \\
\text { weight/day. It was given as } \\
\text { extract of marigold flowers } \\
\text { (Tagetes erecta } \mathrm{L} \text { ) containing } \\
\text { minimum } 80 \% \text { carotenoids of } \\
\text { which } 67 \% \text { is lutein and } 13.5 \% \\
\text { is zeaxanthin isomers. }\end{array}$ & $\begin{array}{l}\text { Body weights, urine parameters (volume, } \\
\text { specific gravity, color, clarity, pH, RBC, } \\
\text { WBC, bilirubin, ketone bodies, proteins, } \\
\text { glucose and nitrite), hematological } \\
\text { analysis, serum parameter analysis } \\
\text { (glucose, urea, creatinine, cholesterol, } \\
\text { triglycerides, AST, ALT, ALP, bilirubin, } \\
\text { sodium, potassium, chloride, total } \\
\text { protein, albumin, globulin and A/G } \\
\text { ratio), and gene mutation }\end{array}$ & $\begin{array}{l}\text { No adverse effect was } \\
\text { observed. } \\
\text { NOAEL: } 400 \mathrm{mg} / \mathrm{kg} / \text { day } \\
\text { HED: } 64.8 \mathrm{mg} / \mathrm{kg} / \text { day }\end{array}$ \\
\hline [85] & $\begin{array}{l}20 \text { rats (10 male, } \\
10 \text { female) }\end{array}$ & 90 days & $\begin{array}{l}\text { Lutein diacetate } 2.1,22.5 \text {, and } \\
210 \mathrm{mg} / \mathrm{kg} \text { body weight/day }\end{array}$ & $\begin{array}{l}\text { Body weights, net body weight gains, } \\
\text { feed intake, neurological observations, } \\
\text { hematology and clinical chemistry }\end{array}$ & $\begin{array}{l}\text { No adverse effect was } \\
\text { observed. It is relatively safe } \\
\text { in rats up to this dose. } \\
\text { NOAEL: } 210 \mathrm{mg} / \mathrm{kg} / \text { day } \\
\text { HED: } 34.02 \mathrm{mg} / \mathrm{kg} / \text { day }\end{array}$ \\
\hline$[20]$ & $\begin{array}{l}70 \text { wistar rats ( } 35 \text { males } \\
\text { and } 35 \text { females) for } \\
\text { short-term toxicity study } \\
\text { and } 70 \text { more rats for } \\
\text { subchronic toxicity study }\end{array}$ & $\begin{array}{l}\text { Short-term toxicity study: } \\
4 \text { weeks, subchronic } \\
\text { toxicity study: } 13 \text { weeks }\end{array}$ & $\begin{array}{l}\text { Lutein and its ester was } \\
\text { administered orally at doses of } \\
\text { 4, 40, and } 400 \mathrm{mg} / \mathrm{kg} \text { body } \\
\text { weight/day }\end{array}$ & $\begin{array}{l}\text { Body weight, food consumption pattern, } \\
\text { organ weight, other adverse side } \\
\text { reactions, alteration in hepatic and renal } \\
\text { function, change in the hematological } \\
\text { parameters and in lipid profile }\end{array}$ & $\begin{array}{l}\text { No adverse effect was } \\
\text { observed. No mortality was } \\
\text { produced by lutein and lutein } \\
\text { ester up to a concentration of } \\
4 \mathrm{~g} / \mathrm{kg} \text {. Lutein and its ester } \\
\text { form was found nontoxic. } \\
\text { NOAEL: } 400 \mathrm{mg} / \mathrm{kg} / \text { day } \\
\text { HED: } 64.8 \mathrm{mg} / \mathrm{kg} / \text { day }\end{array}$ \\
\hline [86] & $\begin{array}{l}80 \text { weanling male albino } \\
\text { mice ( } 50 \text { for acute toxicity } \\
\text { study, } 30 \text { for subacute } \\
\text { toxicity study) }\end{array}$ & $\begin{array}{l}\text { Acute toxicity study: } \\
14 \text { days, subacute toxicity } \\
\text { study: } 4 \text { weeks }\end{array}$ & $\begin{array}{l}\text { Lutein } 0.57,100,1000 \text {, and } \\
10,000 \mathrm{mg} / \mathrm{kg} \text { body weight for } \\
\text { acute toxicity study; } 0,100 \text {, and } \\
1000 \mathrm{mg} / \mathrm{kg} \text { body weight } / \text { day } \\
\text { for subacute toxicity study }\end{array}$ & $\begin{array}{l}\text { Clinical observation, ophthalmic } \\
\text { examinations, body, organ weights, } \\
\text { hematological, histopathological, and } \\
\text { other clinical chemistry parameters }\end{array}$ & $\begin{array}{c}\text { LD50 exceeded 10,000 mg/kg } \\
\text { body weight. No toxicity was } \\
\text { observed up to this dose. } \\
\text { NOAEL: } 1000 \mathrm{mg} / \mathrm{kg} / \text { day } \\
\text { HED: } 81 \mathrm{mg} / \mathrm{kg} / \text { day }\end{array}$ \\
\hline
\end{tabular}


Table 1. Cont.

\begin{tabular}{|c|c|c|c|c|c|}
\hline Reference & $\begin{array}{l}\text { Type and Number of } \\
\text { Animal Used }\end{array}$ & Duration of Therapy & $\begin{array}{l}\text { Name and Dose of } \\
\text { Carotenoids Administered }\end{array}$ & Parameters Observed & Findings and Observation \\
\hline [87] & $\begin{array}{l}90 \text { female swiss albino } \\
\text { mice ( } 50 \text { for acute toxicity } \\
\text { study, } 40 \text { for subacute } \\
\text { toxicity study) }\end{array}$ & $\begin{array}{c}\text { Acute toxicity study: } \\
2 \text { weeks, subacute toxicity } \\
\text { study: } 4 \text { weeks }\end{array}$ & $\begin{array}{l}\text { Lutein-poly-(lactic-co-glycolic } \\
\text { acid) (PLGA)-phospholipid (PL) } \\
\text { nano-capsules 0.1,1,10, and } \\
100 \mathrm{mg} / \mathrm{kg} \text { body weight for } \\
\text { acute toxicity study; } 1 \text { and } \\
10 \mathrm{mg} / \mathrm{kg} \text { body weight/day for } \\
\text { subacute toxicity study }\end{array}$ & $\begin{array}{l}\text { Mortality, ophthalmic examinations, } \\
\text { body and organ weights, hematology, } \\
\text { histopathology and other blood and } \\
\text { tissue clinical chemistry parameters }\end{array}$ & $\begin{array}{l}\text { No toxicity or adverse effect } \\
\text { was observed at a dose of } \\
10 \mathrm{mg} / \mathrm{kg} \text { body weight. } \\
\text { NOAEL: } 10 \mathrm{mg} / \mathrm{kg} / \text { day } \\
\text { HED: } 0.81 \mathrm{mg} / \mathrm{kg} / \text { day }\end{array}$ \\
\hline [88] & 100 SD rats & $\begin{array}{l}\text { Subchronic toxicity: } \\
90 \text { days, acute toxicity: } \\
2 \text { weeks }\end{array}$ & $\begin{array}{c}\text { Maximum tolerable dose was } \\
\text { more than } 10.0 \mathrm{~g} / \mathrm{kg} \text { body } \\
\text { weight (acute oral toxicity tests), } \\
\text { Highest dosage of } \\
300 \mathrm{mg} / \mathrm{kg} / \text { day } \\
\text { meso-zeaxanthin }\end{array}$ & $\begin{array}{c}\text { Acute toxicity, genetic toxicity (Ames } \\
\text { test, mice bone marrow erythrocyte } \\
\text { micronucleus and mice sperm } \\
\text { abnormality) }\end{array}$ & $\begin{array}{l}\text { No acute toxicity and no } \\
\text { genotoxicity was observed. } \\
\text { NOAEL: } 300 \mathrm{mg} / \mathrm{kg} / \text { day } \\
\text { HED: } 48.6 \mathrm{mg} / \mathrm{kg} / \text { day }\end{array}$ \\
\hline [89] & $\begin{array}{l}120 \text { wistar rats ( } 60 \text { males } \\
\text { and } 60 \text { females) }\end{array}$ & 90 days & $\begin{array}{l}\text { Zeaxanthin concentrate at doses } \\
\text { of } 0,4,40 \text {, and } 400 \mathrm{mg} / \mathrm{kg} \text { body } \\
\text { weight } / \text { day for sub-chronic } \\
\text { toxicity study; additional 100, } \\
\text { 200, } 400 \text {, and } 1000 \mathrm{mg} / \mathrm{kg} \text { body } \\
\text { weight } / \text { day; } 4 \mathrm{rats} \text { were given } \\
\text { zeaxanthin } 2000 \mathrm{mg} / \mathrm{kg} \mathrm{bw} / \text { day } \\
\text { for acute toxicity study }\end{array}$ & $\begin{array}{l}\text { Body weight, feed consumption; } \\
\text { ophthalmoscopic examination, clinical } \\
\text { pathology, neurological examination, } \\
\text { clinical chemistry, hematology, urine } \\
\text { analysis, necropsy, organ weight, } \\
\text { histopathology, mutagenic activity }\end{array}$ & $\begin{array}{l}\text { No mortality, toxicity, and } \\
\text { mutagenicity was observed. } \\
\text { NOAEL: } 400 \mathrm{mg} / \mathrm{kg} / \text { day } \\
\text { HED: } 64.8 \mathrm{mg} / \mathrm{kg} / \text { day }\end{array}$ \\
\hline [90] & 50 han wistar rats & $\begin{array}{l}13 \text { weeks followed by a } \\
\text { 4-week recovery period }\end{array}$ & $\begin{array}{l}\text { Meso-zeaxanthin 2, 20, } \\
\text { and } 200 \mathrm{mg} / \mathrm{kg} / \text { day. }\end{array}$ & Potential toxicity and genotoxicity & $\begin{array}{l}\text { No adverse effect was } \\
\text { observed up to } 200 \mathrm{mg} / \mathrm{kg} / \text { day } \\
\text { NOAEL: } 200 \mathrm{mg} / \mathrm{kg} / \text { day } \\
\text { HED: } 32.4 \mathrm{mg} / \mathrm{kg} / \text { day }\end{array}$ \\
\hline
\end{tabular}

aminotransferase; ALT: alanine aminotransferase; ALP: alkaline phosphatase. 
Table 2. Clinical trials of carotenoids against eye disease.

\begin{tabular}{|c|c|c|c|c|c|c|}
\hline Reference & Trial ID & Study Type & Study Duration & $\begin{array}{l}\text { Characteristics of } \\
\text { Participants }\end{array}$ & $\begin{array}{l}\text { Intervention Group(s)/Comparison } \\
\text { Group(s)/Assessment Criteria }\end{array}$ & Result \\
\hline \multirow[b]{2}{*}{ [91] } & \multirow[b]{2}{*}{ NCT00345176 } & \multirow[b]{2}{*}{$\begin{array}{l}\text { Multicenter, } \\
\text { randomized, } \\
\text { double-masked, } \\
\text { placebo-controlled } \\
\text { phase } 3 \text { study }\end{array}$} & \multirow[b]{2}{*}{7 years } & \multirow[b]{2}{*}{$\begin{array}{c}\text { Patients } \\
\mathrm{N}=4203 \\
\text { Age range: } 50-85 \text { years } \\
\text { Age }(\text { mean } \pm \mathrm{SD}): \\
73.1 \pm 7.7 \\
\text { Sex: } 56.8 \% \text { Female }\end{array}$} & $\begin{array}{l}\text { Primary randomization: } \\
\text { G 1: AREDS formulation } \\
\text { G 2: AREDS, L } 10 \mathrm{mg}, \mathrm{Z} 2 \mathrm{mg} \\
\text { G 3: AREDS, DHA } 350 \mathrm{mg}, \text { EPA } 650 \mathrm{mg} \\
\text { G 4: AREDS, L } 10 \mathrm{mg}, \mathrm{Z} 2 \mathrm{mg} \text {, } \\
\text { DHA } 350 \mathrm{mg}, \text { EPA } 650 \mathrm{mg}\end{array}$ & \multirow[b]{2}{*}{$\begin{array}{l}\text { No statistically significant } \\
\text { reduction in progression to } \\
\text { advanced AMD was observed } \\
\quad(p=0.12 \text { for } \mathrm{L}+\mathrm{Z}) .\end{array}$} \\
\hline & & & & & $\begin{array}{c}\text { Secondary randomization: } \\
\text { G 1: AREDS } \\
\text { supplement } \\
\text { G 2: AREDS } \\
\text { supplement with no beta carotene } \\
\text { G 3: AREDS with low dose zinc }(25 \mathrm{mg}) \\
\text { G 4: AREDS } \\
\text { supplement with no beta carotene and } \\
\text { with low-dose zinc }\end{array}$ & \\
\hline [92] & ISRCTN60816411 & $\begin{array}{l}\text { Single-blind, } \\
\text { randomized } \\
\text { controlled clinical } \\
\text { trial }\end{array}$ & 3 years & $\begin{array}{c}\text { Patients } \\
N=67(52 \text { completed } \\
\text { Age (mean } \pm \text { SD): } 66 \pm 8 \\
\text { Sex: } 65.4 \% \text { Female }\end{array}$ & $\begin{array}{c}\text { G 1: } 20 \mathrm{mg} \mathrm{L}, 0.86 \mathrm{mg} \mathrm{Z} \\
\text { G 2: } 10 \mathrm{mg} \mathrm{MZ}, 10 \mathrm{mg} \mathrm{L}, 2 \mathrm{mg} \mathrm{Z} \\
\text { G 3: } 17 \mathrm{mg} \mathrm{MZ}, 3 \mathrm{mg} \mathrm{L}, 2 \mathrm{mg} \mathrm{Z}\end{array}$ & $\begin{array}{c}\text { No statistically significant } \\
\text { change in AMD grade between } \\
\text { intervention groups } \\
(p=0.29, \text { Fisher's exact test). }\end{array}$ \\
\hline [93] & ISRCTN 94557601 & $\begin{array}{l}\text { Randomized } \\
\text { double-masked } \\
\text { placebo-controlled } \\
\text { clinical trial }\end{array}$ & $\begin{array}{l}\text { Each participant } \\
\text { was followed up } \\
\text { for up to } 3 \text { years }\end{array}$ & $\begin{array}{c}\text { Patients } \\
N=433 \\
\text { Age range: } 50-95 \text { years } \\
\text { Age (mean } \pm \text { SD): } \\
75.9 \pm 7.7 \\
\text { Sex: } 57.3 \% \text { Female }\end{array}$ & $\begin{array}{l}\text { G1: A tablet was taken twice daily to } \\
\text { deliver a daily dose of } 12 \mathrm{mg} \mathrm{L}, 0.6 \mathrm{mg} \mathrm{Z} \text {, } \\
15 \mathrm{mg} \mathrm{d}-\alpha \text {-tocopherol, } 150 \mathrm{mg} \text { ascorbic } \\
\text { acid, } 20 \mathrm{mg} \text { zinc oxide, and } 0.4 \mathrm{mg} \\
\text { copper gluconate } \\
\text { G2: Placebo (made up of cellulose, } \\
\text { lactose, and magnesium stearate) }\end{array}$ & $\begin{array}{l}\text { 4.8 letters better BCVA was } \\
\text { seen in active group than } \\
\text { placebo group, which was } \\
\text { statistically significant } \\
(p=0.04) \text {. Visual acuity } \\
\text { increased by } 1.4 \text { letters with } \\
\text { 1-log-unit increase in serum } \\
\text { lutein. Morphologic severity } \\
\text { progressed slowly. }\end{array}$ \\
\hline [94] & ISRCTN 17842302 & $\begin{array}{c}\text { Randomized clinical } \\
\text { trial on participants } \\
\text { with AMD }\end{array}$ & 60 weeks & $\begin{array}{c}\text { Patients } \\
N=14 \\
\text { Age range: } 56-83 \text { years } \\
\text { Age }(\text { mean } \pm S D): \\
67.3 \pm 8.5\end{array}$ & $\begin{array}{l}\text { G1: Ascorbic acid } 150 \mathrm{mg} \text {, cupric oxide } \\
400 \mu \mathrm{g} \text {, DL- } \alpha \text {-tocopherol } 15 \mathrm{mg} \text {, zinc } \\
\text { oxide } 20 \mathrm{mg} \text {, lutein } 12 \mathrm{mg}, \mathrm{Z} 0.6 \mathrm{mg} \text {, EPA } \\
\text { 240 mg, DHA } 840 \mathrm{mg} \\
\text { G2: No supplement }\end{array}$ & $\begin{array}{l}\text { A nonsignificant latency and } \\
\text { reduced amplitudes of } \\
\text { multifocal electroretinography } \\
\text { (mfERG) was seen on } \\
\text { supplement withdrawal (ring } 3 \\
\text { N2 latency, } p=0.041 \text { and ring } 4 \\
\text { P1 latency, } p=0.016 \text { ). }\end{array}$ \\
\hline
\end{tabular}


Table 2. Cont

\begin{tabular}{|c|c|c|c|c|c|c|}
\hline Reference & Trial ID & Study Type & Study Duration & $\begin{array}{l}\text { Characteristics of } \\
\text { Participants }\end{array}$ & $\begin{array}{l}\text { Intervention Group(s)/Comparison } \\
\text { Group(s)/Assessment Criteria }\end{array}$ & Result \\
\hline [95] & - & $\begin{array}{l}\text { Double-blind and } \\
\text { placebo-controlled } \\
\text { clinical trial }\end{array}$ & 140 days & $\begin{array}{c}\text { Patients } \\
N=100 \\
\text { Age range: } 18-64 \text { years } \\
\text { Sex: } 48 \% \text { Female }\end{array}$ & $\begin{array}{c}\text { G1: Placebo } \\
\text { G2: } 5 \mathrm{mg} \mathrm{L} \\
\text { G3: } 10 \mathrm{mg} \mathrm{L} \\
\text { G4: } 20 \mathrm{mg} \mathrm{L} \text { (younger group) } \\
\text { G5: } 20 \mathrm{mg} \mathrm{L} \text { (older group) }\end{array}$ & $\begin{array}{c}\text { A linear, dose-dependent } \\
\text { increase in macular pigment } \\
\text { optical density (MPOD) was } \\
\text { observed ( } p<0.0001)\end{array}$ \\
\hline [96] & NCT00763659 & $\begin{array}{l}\text { A prospective, } \\
\text { randomized } \\
\text { double-blind, placebo } \\
\text { controlled clinical } \\
\text { trial on patients with } \\
\text { non-exudative AMD }\end{array}$ & 12 months & $\begin{array}{c}\text { Patients } \\
N=172 \\
\text { Age (mean } \pm \text { SD): } 70 \pm 10 \\
\text { Sex: } 54.7 \% \text { Female }\end{array}$ & 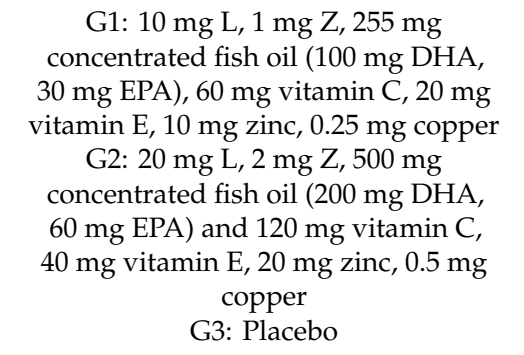 & $\begin{array}{l}\text { Statistically significant increase } \\
\text { in MPOD was seen in both G1 } \\
\text { and G2 }(p<0.001) . \\
\text { Supplementation with L and Z } \\
\text { improved and stabilized BCVA } \\
\text { in AMD patients. }\end{array}$ \\
\hline [97] & - & $\begin{array}{l}\text { Clinical trial on } \\
\text { patients with } \\
\text { unilateral wet AMD } \\
\text { and patients with } \\
\text { unilateral cCSC }\end{array}$ & 6 months & $\begin{array}{c}\text { Patients } \\
N=20 \\
\text { Age: }>56 \text { years } \\
\text { Age (mean } \pm \text { SD): } 66 \pm 4 \\
\text { Sex: } 30 \% \text { Female }\end{array}$ & $\begin{array}{c}\text { Sante Lutax } 20 \text { plus DHA ( } 20 \mathrm{mg} \mathrm{L}, 1 \mathrm{mg} \\
\text { Z, and } 200 \mathrm{mg} \text { DHA) }\end{array}$ & $\begin{array}{l}\text { MPOD }(p=0.032) \text { and contrast } \\
\text { sensitivity }(p<0.05) \text { improved. } \\
\text { L, Z, DHA dietary supplement } \\
\text { had beneficial effects. }\end{array}$ \\
\hline [98] & NCT00909090 & $\begin{array}{l}\text { Randomized, } \\
\text { double-blind, } \\
\text { placebo-controlled } \\
\text { clinical trial }\end{array}$ & 400 days & $\begin{array}{c}\text { Patients } \\
N=115(109 \text { completed }) \\
\text { Age (mean } \pm \text { SD): } 23.2 \pm 4 \\
\text { Sex: } 59.6 \% \text { Female }\end{array}$ & $\begin{array}{l}\text { G1: } 10 \mathrm{mg} \mathrm{L}, 2 \mathrm{mg} \mathrm{Z} \\
\text { G2: Placebo }\end{array}$ & $\begin{array}{c}\text { MPOD }(p<0.0001) \text {, chromatic } \\
\text { contrast }(p<0.0001) \text { and } \\
\text { photostress recovery time }(p= \\
0.002) \text { improved significantly. }\end{array}$ \\
\hline [99] & NCT10528605 & $\begin{array}{l}\text { Randomized, } \\
\text { double-blind, placebo } \\
\text { controlled trial on } \\
\text { patients with early } \\
\text { AMD }\end{array}$ & 2 years & $\begin{array}{c}\text { Patients } \\
N=112 \\
\text { Age: }>50 \text { years } \\
\text { Age }(\text { mean } \pm \text { SD): } \\
69.1 \pm 7.3 \\
\text { Sex: } 57.4 \% \text { Female }\end{array}$ & $\begin{array}{c}\text { G1: Placebo } \\
\text { G2: } 10 \mathrm{mg} \mathrm{L} \\
\text { G3: } 20 \mathrm{mg} \mathrm{L} \\
\text { G4: } \mathrm{L} 10 \mathrm{mg}, \mathrm{Z} 10 \mathrm{mg}\end{array}$ & $\begin{array}{c}\text { MPOD, retinal sensitivity, } \\
\text { N1P1 response densities in ring } \\
1 \text { and ring } 2 \text { increased } \\
\text { significantly in G2, G3, G4 (all } \\
\quad p<0.05 \text { ) }\end{array}$ \\
\hline [100] & ISRCTN54990825 & $\begin{array}{l}\text { A double-blind, } \\
\text { placebo-controlled }\end{array}$ & 12 weeks & $\begin{array}{c}\text { Healthy subjects } \\
N=32 \\
\text { Age range: } 18-25 \text { years }\end{array}$ & $\begin{array}{c}\text { G1: Placebo } \\
\text { G2: } 6.18 \mathrm{mg} \mathrm{L}, 0.73 \mathrm{mg} \mathrm{Z}, 0.53 \mathrm{mg} \mathrm{MZ} \\
\text { (total } 7.44 \mathrm{mg} \text { ) } \\
\text { G3: } 10.86 \mathrm{mg} \mathrm{L}, 1.33 \mathrm{mg} \mathrm{Z}, 0.94 \mathrm{mg} \mathrm{MZ} \\
\text { (total } 13.13 \mathrm{mg} \text { ) } \\
\text { G4: } 22.33 \mathrm{mg} \mathrm{L}, 2.70 \mathrm{mg} \mathrm{Z}, 2 \mathrm{mg} \mathrm{MZ} \\
\text { (total } 27.03 \mathrm{mg} \text { ) }\end{array}$ & $\begin{array}{l}\text { Serum level increased linearly } \\
\text { with increased dose. Group } 3 \\
\text { showed the highest ratio of } \\
\text { MPOD change, which was } \\
\text { statistically significant } \\
(p=0.021) .\end{array}$ \\
\hline
\end{tabular}


Table 2. Cont.

\begin{tabular}{|c|c|c|c|c|c|c|}
\hline Reference & Trial ID & Study Type & Study Duration & $\begin{array}{c}\text { Characteristics of } \\
\text { Participants }\end{array}$ & $\begin{array}{l}\text { Intervention Group(s)/Comparison } \\
\text { Group(s)/Assessment Criteria }\end{array}$ & Result \\
\hline$[101]$ & - & $\begin{array}{l}\text { Randomized, double } \\
\text { masked, } \\
\text { placebo-controlled } \\
\text { trial }\end{array}$ & 10 years & $\begin{array}{c}\text { Patients and healthy } \\
\text { subjects } \\
N=39,876 \\
\text { Age range: } \geq 45 \text { years } \\
\text { Age (mean): } 53.5 \text { (no } \\
\text { cataract), } 61 \text { (cataract) } \\
\text { Sex: } 100 \% \text { Female }\end{array}$ & $\beta$-carotene, vitamin $A$, and vitamin $E$ & $\begin{array}{l}\text { Only } 2031 \text { people developed } \\
\text { cataract. Most of them were } \\
\text { smokers, had high BMI, and } \\
\text { reported a history of } \\
\text { hypertension, diabetes, and } \\
\text { high cholesterol. Higher } \\
\text { dietary intakes of L/Z }(p=0.04) \\
\text { and vitamin E }(p=0.03) \\
\text { significantly decreased the risk } \\
\text { of cataract. }\end{array}$ \\
\hline [102] & - & Prospective study & 5 years & $\begin{array}{c}\text { Patients and healthy } \\
\text { subjects } \\
N=400 \\
\text { Age range: } 50-86 \text { years } \\
\text { Sex: Both male and } \\
\text { Female }\end{array}$ & $\begin{array}{l}\text { No supplement was provided. Serum } \\
\text { concentrations of individual carotenoids, } \\
\alpha \text { - and } \gamma \text {-tocopherol were determined }\end{array}$ & $\begin{array}{l}\text { Serum carotenoids did not } \\
\text { have significant association } \\
\text { with nuclear cataract } \\
\text { prevention }(p=0.13)\end{array}$ \\
\hline [103] & - & Cohort study & 10 years & $\begin{array}{c}\text { Patients and healthy } \\
\text { subjects } \\
N=5925 \\
\text { Age range: } 43-84 \text { years } \\
\text { Sex: Both male and } \\
\text { Female }\end{array}$ & $\begin{array}{l}\text { Intake of } \mathrm{L} \text { and } \mathrm{Z} \text { was assessed using a } \\
\text { food frequency questionnaire }\end{array}$ & $\begin{array}{l}\mathrm{L} \text { (intake in the distant past) } \\
\text { had protective influence on the } \\
\text { development of nuclear } \\
\text { cataracts }(p=0.002) .\end{array}$ \\
\hline$[104]$ & - & Prospective study & 8 years & $\begin{array}{l}\text { Patients and healthy } \\
\text { subjects } \\
N=36,644 \\
\text { Age range: } 45-75 \text { years } \\
\text { Sex: } 0 \% \text { Female }\end{array}$ & Dietary questionnaire was used to assess & $\begin{array}{l}\text { A statistically significant lower } \\
\text { risk of cataract in higher } \\
\text { intakes of } L \text { and } Z \text { was } \\
\text { observed ( } p=0.03) \text {. No impact } \\
\text { of other carotenoids } \\
\text { ( } \alpha \text {-carotene, } \beta \text {-carotene, } \\
\text { lycopene, and } \beta \text {-cryptoxanthin) } \\
\text { are found in cataract } \\
\text { prevention }\end{array}$ \\
\hline [105] & - & $\begin{array}{l}\text { Prospective cohort } \\
\text { study }\end{array}$ & 12 years & $\begin{array}{c}\text { Patients and healthy } \\
\text { subjects } \\
\quad N=77,466 \\
\text { Age range: } 45-71 \text { years }\end{array}$ & $\begin{array}{l}\text { Food frequency questionnaire was used } \\
\text { to assess }\end{array}$ & $\begin{array}{l}\text { Foods rich in carotenoids (L } \\
\text { and Z) decreased the risk of } \\
\text { cataracts }(22 \%)(p=0.04) .\end{array}$ \\
\hline
\end{tabular}


Table 2. Cont

\begin{tabular}{|c|c|c|c|c|c|c|}
\hline Reference & Trial ID & Study Type & Study Duration & $\begin{array}{c}\text { Characteristics of } \\
\text { Participants }\end{array}$ & $\begin{array}{l}\text { Intervention Group(s)/Comparison } \\
\text { Group(s)/Assessment Criteria }\end{array}$ & Result \\
\hline [106] & NCT00000145 & $\begin{array}{l}\text { Clinic-based, baseline } \\
\text { cross-sectional and } \\
\text { prospective cohort } \\
\text { study }\end{array}$ & 9.6 years & $\begin{array}{c}\text { Patients } \\
N=3115 \\
\text { Age range: } 55-80 \text { years } \\
\text { Sex: Both male and } \\
\text { Female }\end{array}$ & Food frequency questionnaires & $\begin{array}{l}\text { No significant association of } \mathrm{L} \\
\text { plus } \mathrm{Z} \text { intake with the } \\
\text { development of nuclear or } \\
\text { cortical lens opacity. }\end{array}$ \\
\hline [107] & NCT00000145 & $\begin{array}{l}\text { 11-center age-related } \\
\text { eye disease study } \\
\text { double-masked } \\
\text { clinical trial }\end{array}$ & 6.3 years & $\begin{array}{c}\text { Patients } \\
N=4757 \\
\text { Age range: } 55-80 \text { years } \\
\text { Sex: } 56 \% \text { Female }\end{array}$ & $\begin{array}{l}\text { G1: Antioxidants ( } \beta \text {-carotene } 15 \mathrm{mg} \text {, } \\
\text { vitamin C } 500 \mathrm{mg} \text {; vitamin E, } 400 \mathrm{IU} \text { ) } \\
\text { G2: Antioxidants (vitamin C, } 500 \mathrm{mg} \text {; } \\
\text { vitamin E, } 400 \mathrm{IU} \text {; and } \beta \text {-carotene, } \\
15 \mathrm{mg} \text { ) + zinc } 80 \mathrm{mg}+\text { copper } 2 \mathrm{mg} \\
\text { G3: Zinc } 80 \mathrm{mg}+\text { copper } 2 \mathrm{mg} \\
\text { G4: Placebo }\end{array}$ & $\begin{array}{l}\text { No statistically significant } \\
\text { effect was observed on the } \\
\text { progression or prevention of } \\
\text { cataract, age-related macular } \\
\text { degeneration, age-related lens } \\
\text { opacities, or visual acuity loss. }\end{array}$ \\
\hline [108] & NCT00345176 & $\begin{array}{l}\text { Randomized, } \\
\text { double-masked, } \\
\text { controlled clinical } \\
\text { trial, cohort study. }\end{array}$ & 5 years & $\begin{array}{c}\text { Patients } \\
N=4203 \\
\text { Age range: } 50-80 \text { years } \\
\text { Sex: } 56.8 \% \text { Female }\end{array}$ & $\begin{array}{c}\text { G1: Control group } \\
\text { G2: L } 10 \mathrm{mg} \text { and Z } 2 \mathrm{mg} \\
\text { G3: Docosahexaenoic acid } \\
\text { (DHA } 350 \mathrm{mg} \text { ) and eicosapentaenoic } \\
\text { acid (EPA } 650 \mathrm{mg} \text { ) } \\
\text { G4: L } 10 \mathrm{mg} \text { and } \mathrm{Z} 2 \mathrm{mg}, \\
\text { docosahexaenoic acid (DHA } 350 \mathrm{mg} \text { ) } \\
\text { and eicosapentaenoic acid (EPA } 650 \mathrm{mg} \text { ) }\end{array}$ & $\begin{array}{l}\text { Carotenoid supplementation } \\
\text { did not have any significant } \\
\text { positive or negative impact on } \\
\text { the high mortality rate } \\
\text { observed in people having } \\
\text { age-related macular disease. }\end{array}$ \\
\hline [109] & - & $\begin{array}{l}\text { Randomized, } \\
\text { double-masked, } \\
\text { placebo-controlled } \\
\text { trial }\end{array}$ & 12 years & $\begin{array}{l}\text { Patients and healthy } \\
\text { subjects } \\
N=22,071 \\
\text { Age range: } 40-84 \text { years } \\
\text { Sex: } 0 \% \text { Female }\end{array}$ & $\beta$-carotene $(50 \mathrm{mg}$ ) or placebo & $\begin{array}{l}\beta \text {-carotene supplementation } \\
\text { had no overall beneficial or } \\
\text { harmful effect on cataract or } \\
\text { cataract extraction. }\end{array}$ \\
\hline [110] & NCT00000479 & $\begin{array}{l}\text { Randomized, double } \\
\text { masked, } \\
\text { placebo-controlled } \\
\text { trial }\end{array}$ & 2.1 years & $\begin{array}{l}\text { Patients and healthy } \\
\text { subjects } \\
N=39,876 \\
\text { Age: } \geq 45 \text { years } \\
\text { Sex: } 100 \% \text { Female }\end{array}$ & $\begin{array}{l}\text { G1: } \beta \text {-carotene } \\
\text { G2: Placebo }\end{array}$ & $\begin{array}{l}\text { No large beneficial or harmful } \\
\text { effect was found on the } \\
\text { development of cataract. }\end{array}$ \\
\hline [111] & - & $\begin{array}{c}\text { Multi-centered, } \\
\text { prospective, } \\
\text { double-masked, } \\
\text { randomized, } \\
\text { placebo-controlled } \\
\text { trial }\end{array}$ & 3 years & $\begin{array}{c}\text { Patients } \\
N=445 \\
\text { Age }(\text { mean } \pm \mathrm{SD}) \text { : } \\
66.2 \pm 8.9 \\
\text { Sex: } 59.3 \% \text { Female }\end{array}$ & $\begin{array}{c}\text { G1: } 6 \mathrm{mg} \beta \text {-carotene, } 200 \mathrm{mg} \\
\alpha \text {-tocopherol acetate (Vitamin E) and } \\
250 \mathrm{mg} \text { ascorbic acid } \\
\text { G2: Placebo }\end{array}$ & $\begin{array}{l}\text { A small, statistically significant } \\
\text { reduction in the progression of } \\
\text { age-related cataract was } \\
\text { observed after three years of } \\
\text { treatment }(p=0.048) .\end{array}$ \\
\hline
\end{tabular}


Table 2. Cont

\begin{tabular}{|c|c|c|c|c|c|c|}
\hline Reference & Trial ID & Study Type & Study Duration & $\begin{array}{l}\text { Characteristics of } \\
\text { Participants }\end{array}$ & $\begin{array}{c}\text { Intervention Group(s)/Comparison } \\
\text { Group(s)/Assessment Criteria }\end{array}$ & Result \\
\hline [112] & NCT00342992 & $\begin{array}{l}\text { Randomized, } \\
\text { double-blind, } \\
\text { placebo-controlled } \\
\text { clinical trial }\end{array}$ & $\begin{array}{c}5 \text { to } 8 \text { years } \\
\text { (median } 6.6 \text { years) }\end{array}$ & $\begin{array}{c}\text { Patients } \\
N=1828 \\
\text { Age range: } 50-69 \text { years } \\
\text { Sex: } 0 \% \text { Female }\end{array}$ & $\begin{array}{c}\text { G1: } \alpha \text {-tocopherol } 50 \mathrm{mg} / \mathrm{day}, \\
\text { G2: } \beta \text {-carotene } 20 \mathrm{mg} / \mathrm{day}, \\
\text { G2: A combination of the two } \\
\text { G4: placebo }\end{array}$ & $\begin{array}{l}\text { No influence of } \\
\text { supplementation on cataract } \\
\text { prevalence. }\end{array}$ \\
\hline [113] & NCT0140845 & $\begin{array}{c}\text { Prospective, } \\
\text { randomized, } \\
\text { double-masked } \\
\text { multicenter study }\end{array}$ & 24 months & $\begin{array}{c}\text { Patients } \\
N=126 \\
\text { Age }(\text { mean } \pm \text { SD): } \\
75.3 \pm 7.6 \\
\text { Sex: } 58.7 \% \text { Female }\end{array}$ & $\begin{array}{l}\text { G1: Carotenoids ( } 5 \mathrm{mg} \text { of } \mathrm{L} \text { and } 1 \mathrm{mg} \text { of } \\
\text { Z) + (560 mg of DHA, } 420 \mathrm{mg} \text { GLA, } \\
80 \mathrm{mg} \text { of vitamin C, } 10 \mathrm{mg} \text { of vitamin E, } \\
2 \mathrm{mg} \text { of vitamin B6, } 200 \mathrm{~g} \text { of Vitamin B9, } \\
1 \mathrm{~g} \text { of vitamin B12, } 10 \mathrm{mg} \text { of Zinc) } \\
\text { G2: Placebo }+(560 \mathrm{mg} \text { of DHA, } 420 \mathrm{mg} \\
\text { GLA, } 80 \mathrm{mg} \text { of vitamin C, } 10 \mathrm{mg} \text { of } \\
\text { vitamin E, } 2 \mathrm{mg} \text { of vitamin B6, } 200 \mathrm{~g} \text { of } \\
\text { Vitamin B9, } 1 \mathrm{~g} \text { of vitamin B12, } 10 \mathrm{mg} \\
\text { of Zinc) }\end{array}$ & $\begin{array}{c}\text { Carotenoid supplementation } \\
\text { did not improve MPOD, which } \\
\text { was exacerbated by cataract } \\
\text { and age-related macular } \\
\text { degeneration. }\end{array}$ \\
\hline [114] & - & $\begin{array}{l}\text { Randomized, } \\
\text { double-blind, } \\
\text { placebo-controlled } \\
\text { supplementation } \\
\text { study }\end{array}$ & 2 years & $\begin{array}{c}\text { Patients } \\
N=17 \\
\text { Age range: } 55-73 \text { years } \\
\text { Sex: } 86.7 \% \text { Female }\end{array}$ & $\begin{array}{c}\text { G1: } 12 \mathrm{mg} \text { of all-trans-lutein, } 3 \mathrm{mg} \text { of } \\
\text { 13/15-cis-lutein, } 3.3 \mathrm{mg} \text { of } \\
\text { alpha-tocopherol } \\
\text { G2: } 100 \mathrm{mg} \text { of alpha-tocopherol } \\
\text { G3: Placebo }(0.06 \mathrm{mg} \text { of } \\
\text { alpha-tocopherol, } 0.23 \mathrm{mg} \text { of } \\
\text { gamma-tocopherol, } 500 \mathrm{mg} \text { of corn oil) }\end{array}$ & $\begin{array}{l}\text { L has beneficial effect on } \\
\text { age-related cataracts, whereas } \\
\text { alpha-tocopherol was not } \\
\text { beneficial. }\end{array}$ \\
\hline [115] & NCT01269697 & $\begin{array}{l}\text { Phase 3, double-blind, } \\
\text { randomized clinical } \\
\text { trial }\end{array}$ & 6 months & $\begin{array}{c}\text { Healthy subjects } \\
N=120 \\
\text { Age range: } 40-70 \text { years } \\
\text { Age }(\text { mean } \pm S D): \\
56.7 \pm 6.6 \\
\text { Sex: } 71.7 \% \text { Female }\end{array}$ & $\begin{array}{c}\text { G1: L } 5 \mathrm{mg}, \mathrm{Z} 1 \mathrm{mg} \text {, vitamin C ( } 90 \mathrm{mg}), \\
\text { vitamin E (15 mg), zinc }(7.5 \mathrm{mg}), \text { copper } \\
(<0.5 \mathrm{mg}) \text {, and resveratrol }(0.5 \mathrm{mg}), \\
33 \mathrm{mg} \text { of fish oil }(50 \% \omega-3) \\
\text { G2: Placebo }\end{array}$ & $\begin{array}{c}\text { An increase in plasma } L \text { and } Z \\
\text { concentrations was observed } \\
(p<0.005) \text { but no elevation of } \\
\text { MPOD was found. }\end{array}$ \\
\hline [116] & NCT00029289 & $\begin{array}{l}\text { Double-masked } \\
\text { randomized } \\
\text { placebo-controlled } \\
\text { clinical trial with a } \\
\text { crossover design }\end{array}$ & 24 weeks & $\begin{array}{c}\text { Patients } \\
N=34 \\
\text { Age (mean } \pm \text { SD): } 49.2 \pm 9 \\
\text { Sex: } 61.8 \% \text { Female }\end{array}$ & $\begin{array}{l}\text { G1: L } 10 \mathrm{mg} / \mathrm{d} \text { for } 12 \text { weeks, } 30 \mathrm{mg} / \mathrm{d} \text { for } \\
\text { next } 12 \text { weeks, followed by placebo for } \\
24 \text { weeks } \\
\text { G2: Placebo } 24 \text { weeks, followed by L } 10 \\
\text { mg/d for } 12 \text { weeks, followed by } 30 \mathrm{mg} / \mathrm{d} \\
\text { for next } 12 \text { weeks }\end{array}$ & $\begin{array}{l}\text { Significantly improved visual } \\
\text { field ( } p=0.038 \text { ), slightly } \\
\text { improved visual acuity. } \\
\text { L 10-30 mg/day for up to } \\
6 \text { months was safe. }\end{array}$ \\
\hline
\end{tabular}

AREDS: Age-Related Eye Disease Study; AREDS formulation: vitamin $500 \mathrm{mg}$, vitamin E $400 \mathrm{IU}, \beta$-carotene $15 \mathrm{mg}$, zinc $80 \mathrm{mg}$ (as zinc oxide), and copper $2 \mathrm{mg}$ (as cupric oxide); BCVA: best-corrected visual acuity; ISRCTN: International Standard Randomized Controlled Trial Number; mfERG: multifocal electroretinography; ARM: age-related maculopathy; AMD; age-related macular degeneration; EPA: eicosapentaenoic acid; DHA: docosahexaenoic acid; BCVA: best-corrected visual acuity; GLA: gamma linolenic acid; MPOD: macular pigment optical density; L: lutein; Z: zeaxanthin; MZ: mesozeaxanthin; ARM: age-related maculopathy; cCSC: chronic central serous chorioretinopathy; BMI: body mass index. 
Preclinical study results listed in Table 1 have established the safety profile of several carotenoids. Results from different clinical trials listed in Table 2 confirm that an increased serum level of lutein was correlated with enhanced visual acuity $[93,96,116]$. An increase in macular pigment optical density (MPOD) was seen with lutein and zeaxanthin supplementation [95-100]. Several studies reported that lutein and zeaxanthin administration was associated with a reduced risk of cataract [101-105,114]. Nonetheless, some studies did not find statistically significant effects of lutein and zeaxanthin on prevention of eye diseases or enhancement of macular pigments [99,102,113,115]. In a study by Manayi et al. (2015), lutein and zeaxanthin were found in the lens, but $\beta$-carotene and lycopene were not detected [8]. Among six clinical trials mentioned in Table 2, which examined the effects of $\beta$-carotene on cataract, five found no significant impact $[104,107,109,112]$, and one showed a small reduction in the progression of age-related cataract [111]. A study found that smokers, people with high BMI, a history of hypertension, diabetes, and high cholesterol developed cataracts even after taking antioxidants [101]. These studies suggest that $\beta$-carotene is not adequate for cataract prevention as the lens does not contain any $\beta$-carotene. On the contrary, in vivo studies on animals showed that lutein is safe even at a very high dose, and the $\mathrm{LD}_{50}$ of lutein exceeded $10,000 \mathrm{mg} / \mathrm{kg}$ body weight [86]. Eight in vivo studies were mentioned in this review (Table 1), and none of these studies observed any significant adverse effect or toxicity. Xu et al. (2013) suggested a daily intake of $3 \mathrm{mg} / \mathrm{kg} / \mathrm{day}$ meso-zeaxanthin for human [88]. Intake of up to $20 \mathrm{mg} /$ day for lutein was found to be safe for humans [117].

\section{Conclusions}

In this review, we summarized the detrimental effects of ocular oxidative stress generated from the continuous exposure of ultraviolet and blue lights. Then we discussed the protective roles of carotenoids, namely $\beta$-carotene, lutein, and zeaxanthin, against three distinct eye diseases, highlighting the outcomes from the clinical trials. A considerable number of studies including preclinical and clinical trials demonstrated that $\beta$-carotene, lutein, and zeaxanthin can prevent the progression of eye diseases, mainly by quenching free radicals and preventing oxidative damage to the retina. According to study outcomes, it is obvious that $\beta$-carotene, lutein, and zeaxanthin can efficiently attenuate oxidative stress in vivo and confer protection to the eye.

The biological functions of different carotenoids in human are established. As the human body cannot synthesize this important class of molecules, they must be supplied as dietary intake or food/pharmaceutical supplement. Thus, the optimum levels of cellular concentrations of $\beta$-carotene, lutein, and zeaxanthin in eye tissue may help maintain eye health. It is noteworthy that carotenoids, particularly MP, can be assessed noninvasively in retina; such assessment may be useful to determine the average dietary intake of lutein and zeaxanthin to meet the regular need of these molecules [118]. It has been shown that MP attenuates oxidative stress and slows down the progression of apoptosis, mitochondrial dysfunction, and inflammation in diabetes, which can be improved by increasing dietary supplementation of lutein and zeaxanthin [77].

A long-term cohort study by $\mathrm{Wu}$ et al. (2015) found a remarkable $40 \%$ reduced risk of advanced AMD progression for predicted plasma lutein/zeaxanthin scores [119]. Nevertheless, carotenoids show a high degree of variability in bioavailability, which poses a challenge for finding suitable forms (as foods, supplements, or medicines) that can be administered to the patients with AMD. Gastrointestinal absorption and subsequent distribution to ocular tissues are influenced by dietary factors, formulations, gender, age, disease states, and individual genetic variations [120,121]. A recent study found a significantly higher absorption of zeaxanthin and meso-zeaxanthin from a diacetate micromicelle preparation than free carotenoid preparations [120]. Intriguingly, a nano-formulation of lutein-poly-(lactic-co-glycolic acid) (PLGA)-phospholipid (PL) showed a significantly elevated level of lutein in plasma when administered at a lower dose in mice [87]. Novel drug delivery systems and formulations thus could further be exploited to achieve favorable pharmacokinetic and pharmacodynamic profiles of macular xanthophylls in humans. In addition, long-term clinical trials 
with large numbers of populations may be undertaken to confirm the effects of these molecules. Future studies will substantiate the therapeutic potentials of different $\beta$-carotenoids.

Author Contributions: H.M.R. conceptualized, designed and made the final correction of the manuscript. F.T.J. curated data and prepared the original draft. A.K.B. reviewed and edited the manuscript. A.T.B. critically read and revised. All authors have read and agreed to the final version of the manuscript.

Funding: This research received no external funding.

Acknowledgments: The authors would like to thank Razmin Bari for proof reading.

Conflicts of Interest: The authors declare no conflict of interest.

\section{References}

1. Abu-Amero, K.K.; Kondkar, A.A.; Chalam, K.V. Resveratrol and ophthalmic diseases. Nutrients 2016, 8, 200. [CrossRef]

2. Flaxman, S.R.; Bourne, R.R.A.; Resnikoff, S.; Ackland, P.; Braithwaite, T.; Cicinelli, M.; Das, A.; Jonas, J.; Keeffe, J.; Kempen, J. Global causes of blindness and distance vision impairment 1990-2020: A systematic review and meta-analysis. Lancet Glob. Health 2017, 5, 1221-1234. [CrossRef]

3. Kowluru, R.A.; Zhong, Q.; Santos, J.M.; Thandampallayam, M.; Putt, D.; Gierhart, D.L. Beneficial effects of the nutritional supplements on the development of diabetic retinopathy. Nutr. Metab. (Lond.) 2014, 11, 1-10. [CrossRef] [PubMed]

4. Javitt, J.; Wang, F.; West, S. Blindness Due to Cataract: Epidemiology and Prevention. Annu. Rev. Public Health 1996, 17, 159-177. [CrossRef]

5. Subczynski, W.; Wisniewska, A.; Widomska, J. Location of macular xanthophylls in the most vulnerable regions of photoreceptor outer-segment membranes. Arch. Biochem. Biophys. 2010, 504, 61-66. [CrossRef]

6. Snodderly, D.M.; Auran, J.D.; Delori, F.C. The macular pigment. II. Spatial distribution in primate retinas. Investig. Ophthalmol. Vis. Sci. 1984, 25, 674-685.

7. Hammond, B.R., Jr.; Wooten, B.R.; Snodderly, D.M. Individual variations in the spatial profile of human macular pigment. J. Opt. Soc. Am. B 1997, 14, 1187-1196. [CrossRef]

8. Manayi, A.; Abdollahi, M.; Raman, T.; Nabavi, S.; Habtemariam, S.; Daglia, M.; Nabavi, S.M. Lutein and cataract: From bench to bedside. Crit. Rev. Biotechnol. 2015, 36, 829-839. [CrossRef]

9. Fraser, P.; Bramley, P. The biosynthesis and nutritional uses of carotenoids. Prog. Lipid Res. 2004, 43, 228-265. [CrossRef]

10. Saini, R.K.; Nile, S.H.; Park, S.W. Carotenoids from fruits and vegetables: Chemistry, analysis, occurrence, bioavailability and biological activities. Food Res. Int. 2015, 76, 735-750. [CrossRef]

11. Tapiero, H.; Townsend, D.M.; Tew, K.D. The role of carotenoids in the prevention of human pathologies. Biomed. Pharm. 2004, 58, 100-110. [CrossRef]

12. Namitha, K.K.; Negi, P.S. Chemistry and biotechnology of carotenoids. Crit. Rev. Food Sci. Nutr. 2010, 50, 728-760. [CrossRef]

13. Stahl, W.; Sies, H. Bioactivity and protective effects of natural carotenoids. Biochim. Biophys. Acta 2005, 1740, 101-107. [CrossRef]

14. Jomova, K.; Valko, M. Health protective effects of carotenoids and their interactions with other biological antioxidants. Eur. J. Med. Chem. 2013, 70, 102-110. [CrossRef]

15. Nakagawa, K.; Kiko, T.; Hatade, K.; Asai, A.; Kimura, F.; Sookwong, P.; Tsuduki, T.; Arai, H.; Miyazawa, T. Development of a high-performance liquid chromatography-based assay for carotenoids in human red blood cells: Application to clinical studies. Anal. Biochem. 2008, 381, 129-134. [CrossRef]

16. Priyadarshani, A. Insights of hypercarotenaemia: A brief review. Clin. Nutr. Espen. 2018, 23, 19-24. [CrossRef]

17. Rutz, J.K.; Borges, C.D.; Zambiazi, R.C.; da Rosa, C.G.; da Silva, M.M. Elaboration of microparticles of carotenoids from natural and synthetic sources for applications in food. Food Chem. 2016, 202, 324-333. [CrossRef]

18. Britton, G. Structure and properties of carotenoids in relation to function. FASEB J. 1995, 9, 1551-1558. [CrossRef] 
19. Milani, A.; Basirnejad, M.; Shahbazi, S.; Bolhassani, A. Carotenoids: Biochemistry, pharmacology and treatment. Br. J. Pharmacol. 2016, 174, 1290-1324. [CrossRef]

20. Harikumar, K.; Nimita, C.; Preethi, K.; Kuttan, R.; Shankaranarayana, M.; Deshpande, J. Toxicity Profile of Lutein and Lutein Ester Isolated from Marigold Flowers (Tagetes erecta). Int. J. Toxicol. 2008, 27, 1-9. [CrossRef]

21. Krinsky, N.; Landrum, J.; Bone, R. Biologicmechanisms of the protective role of lutein and zeaxanthin in the eye. Annu. Rev. Nutr. 2003, 23, 171-201. [CrossRef] [PubMed]

22. Arunkumar, R.; Calvo, C.M.; Conrady, C.D.; Bernstein, P.S. What do we know about the macular pigment in AMD: The past, the present, and the future. Eye 2018, 32, 992-1004. [CrossRef] [PubMed]

23. Beatty, S.; Koh, H.; Henson, D.; Boulton, M. The Role of Oxidative Stress in the Pathogenesis of Age-Related Macular Degeneration. Surv. Ophthalmol. 2000, 45, 115-134. [CrossRef]

24. Ouyang, X.; Yang, J.; Hong, Z.; Wu, Y.; Xie, Y.; Wang, G. Mechanisms of blue light-induced eye hazard and protective measures: A review. Biomed. Pharmacother. 2020, 130, 110577. [CrossRef] [PubMed]

25. Ahuja, S.; Crocker, E.; Eilers, M.; Hornak, V.; Hirshfeld, A.; Ziliox, M.; Syrett, N.; Reeves, P.J.; Khorana, H.G.; Sheves, M.; et al. Location of the Retinal Chromophore in the Activated State of Rhodopsin. J. Biol. Chem. 2009, 284, 10190-10201. [CrossRef] [PubMed]

26. Hubbard, R.; Wald, G.J. Cis-Trans Isomers of Vitamin a and Retinene in the Rhodopsin System. Gen. Physiol. 1952, 36, 269-315. [CrossRef] [PubMed]

27. Bhosale, P.; Larson, A.; Frederick, J.; Southwick, K.; Thulin, C.; Bernstein, P. Identification and Characterization of a Pi Isoform of GlutathioneS-Transferase (GSTP1) as a Zeaxanthin-binding Protein in the Macula of the Human Eye. J. Biol. Chem. 2004, 279, 49447-49454. [CrossRef]

28. Bhosale, P.; Li, B.; Sharifzadeh, M.; Gellermann, W.; Frederick, J.; Tsuchida, K.; Bernstein, P.S. Purification and Partial Characterization of a Lutein-Binding Protein from Human Retina. Biochemistry 2009, 48, 4798-4807. [CrossRef]

29. Conn, P.F.; Schalch, W.; Truscott, T.G. The singlet oxygen and carotenoid interaction. J. Photochem. Photobiol. 1991, 11, 41-47. [CrossRef]

30. Oliveros, E.; Braun, A.M.; Aminian-Saghafi, T.; Sliwka, H. Quenching of singlet oxygen (1Dg) by carotenoid derivatives: Kinetic analysis by near infra-red luminescence. New J. Chem. 1994, 18, 535-539.

31. Krinsky, N.I.; Deneke, S.M. Interaction of oxygen and oxy-radicals with carotenoids. J. Natl. Cancer Inst. 1982, 69, 205-210. [CrossRef] [PubMed]

32. Woodall, A.A.; Britton, G.; Jackson, M.J. Carotenoids and protection of phospholipids in solution or in liposomes against oxidation by peroxyl radicals: Relationship between carotenoid structure and protective ability. Biochim. Biophys. Acta 1997, 1336, 575-586. [CrossRef]

33. Landrum, J.; Bone, R.; Joa, H.; Kilburn, M.; Moore, L.; Sprague, K. A One Year Study of the Macular Pigment: The Effect of 140 Days of a Lutein Supplement. Exp. Eye Res. 1997, 65, 57-62. [CrossRef] [PubMed]

34. Spector, A. Oxidative stress-induced cataract: Mechanisms of action. FASEB 1995, 9, 1173-1182. [CrossRef]

35. Meyer, C.H.; Sekundo, W. Nutritional Supplementation to Prevent Cataract Formation. Dev. Ophthalmol. 2005, 38, 103-119.

36. Kiziltoprak, H.; Tekin, K.; Inanc, M.; Goker, Y. Cataract in diabetes mellitus. World J. Diabetes 2019, 10, 140-153. [CrossRef]

37. Brown, G.C.; Brown, M.M.; Busbee, B.G. Cost-utility analysis of cataract surgery in the United States for the year 2018. J. Cataract. Refract. Surg. 2019, 45, 927-938. [CrossRef]

38. Cumming, R.G.; Mitchell, P. Alcohol, smoking, and cataracts: The Blue Mountains Eye Study. Arch. Ophthalmol. 1997, 115, 1296-1303. [CrossRef]

39. Masters, P.M.; Bada, J.L.; Zigler, J.S. Aspartic acid racemisation in the human lens during ageing and in cataract formation. Nature 1977, 268, 71-73. [CrossRef]

40. Garner, W.H.; Spector, A. Racemization in human lens: Evidence of rapid insolubilization of specific polypeptides in cataract formation. Proc. Natl. Acad. Sci. USA 1978, 75, 3618-3620. [CrossRef]

41. Gupta, S.; Selvan, V.; Agrawal, S.; Saxena, R. Advances in pharmacological strategies for the prevention of cataract development. Indian J. Ophthalmol. 2009, 57, 175-183. [CrossRef]

42. Micelli-Ferrari, T.; Vendemiale, G.; Grattagliano, I.; Boscia, F.; Arnese, L.; Altomare, E.; Cardia, L. Role of lipid peroxidation in the pathogenesis of myopic and senile cataract. J. Ophthalmol. 1996, 80, 840-843. [CrossRef] [PubMed] 
43. Kaur, A.; Gupta, V.; Christopher, A.F.; Mali, M.A.; Bansal, P. Nutraceuticals in prevention of cataract-An evidence based approach. Saudi J. Ophthalmol. 2017, 31, 30-37. [CrossRef] [PubMed]

44. Truscott, R.J.; Augusteyn, R.C. Oxidative Changes in Human Lens Proteins during Senile Nuclear Cataract Formation. Biochim. Biophys. Acta 1977, 492, 43-52. [CrossRef]

45. Truscott, R.J.W. Age-related nuclear cataract: A lens transport problem. Ophthalmic Res. 2000, 32, 185-194. [CrossRef]

46. Garner, M.H.; Spector, A. Sulfur oxidation in selected human cortical cataracts and nuclear cataracts. Exp. Eye Res. 1980, 31, 361-369. [CrossRef]

47. Bhuyan, K.C.; Bhuyan, D.K. Lipid peroxidation in cataract of the human. Life Sci. 1986, 38, $1463-1471$. [CrossRef]

48. Kellogg III, E.W.; Fridovich, I. Superoxide, hydrogen peroxide, and singlet oxygen in lipid peroxidation by a xanthine oxidase system. J. Biol. Chem. 1975, 250, 8812-8817.

49. Babizhayev, M.A. Failure to withstand oxidative stress induced by phospholipid hydroperoxides as a possible cause of the lens opacities in systemic diseases and ageing. Biochim. Biophys. Acta 1996, 1315, 87-99. [CrossRef]

50. Christen, W.G. Antioxidants and eye disease. Am. J. Med. 1994, 97, 7-14. [CrossRef]

51. Yeum, K.J.; Taylor, A.; Tang, G.; Russell, R.M. Measurement of carotenoids, retinoids, and tocopherols in human lenses. Investig. Ophthalmol. Vis. Sci. 1995, 36, 2756-2761.

52. Yeum, K.J.; Shang, F.; Schalch, W.; Russell, R.M.; Taylor, A. Fat-soluble nutrient concentrations in different layers of human cataractous lens. Curr. Eye Res. 1999, 19, 502-505. [CrossRef] [PubMed]

53. Gao, S.; Qin, T.; Liu, Z.; Caceres, M.A.; Ronchi, C.F.; Chen, O.; Yeum, K.; Taylor, A.; Blumberg, J.B.; Liu, Y.; et al. Lutein and zeaxanthin supplementation reduces $\mathrm{H}_{2} \mathrm{O}_{2}$ induced oxidative damage in human lens epithelial cells. Mol. Vis. 2011, 17, 3180-3190.

54. Chang, D.; Zhang, X.; Rong, S.; Sha, Q.; Liu, P.; Han, T.; Pan, H. Serum antioxidative enzymes levels and oxidative stress products in age-related cataract patients. Oxid. Med. Cell. Longev. 2013, 2013, 587826. [CrossRef]

55. Kaur, J.; Kukreja, S.; Kaur, A.; Malhotra, N.; Kaur, R. The oxidative stress in cataract patients. J. Clin. Diagn. Res. 2012, 6, 1629-1632. [CrossRef] [PubMed]

56. Girach, A.; Manner, D.; Porta, M. Diabetic microvascular complications: Can patients at risk be identified? A review. Int. J. Clin. Pract. 2006, 60, 1471-1483. [CrossRef] [PubMed]

57. Klein, R.; Klein, B.E.K.; Moss, S.E. Relation of Glycemic Control to Diabetic Microvascular Complications in Diabetes Mellitus. Ann. Intern. Med. 1996, 124, 90-96. [CrossRef] [PubMed]

58. Song, K.H.; Jeong, J.S.; Kim, M.K.; Kwon, H.S.; Baek, K.H.; Ko, S.H.; Ahn, Y.B. Discordance in risk factors for the progression of diabetic retinopathy and diabetic nephropathy in patients with type 2 diabetes mellitus. J. Diabetes Investig. 2019, 10, 745-752. [CrossRef]

59. Roohbakhsh, A.; Karimi, G.; Iranshahi, M. Carotenoids in the treatment of diabetes mellitus and its complications: A mechanistic review. Biomed. Pharm. 2017, 91, 31-42. [CrossRef]

60. Julia, M.S.; Ghulam, M.; Qing, Z.; Renu, A.K. Diabetic Retinopathy, Superoxide Damage and Antioxidants. Curr. Pharm. Biotechnol. 2011, 12, 352-361. [CrossRef]

61. Madsen-Bouterse, S.A.; Kowluru, R.A. Oxidative stress and diabetic retinopathy: Pathophysiological mechanisms and treatment perspectives. Rev. Endocr. Metab. Disord. 2008, 9, 315-327. [CrossRef]

62. Kim, D.; Lee, D.; Trackman, P.C.; Roy, S. Effects of High Glucose-Induced Lysyl Oxidase Propeptide on Retinal Endothelial Cell Survival: Implications for Diabetic Retinopathy. J. Pathol. 2019, 189, 1945-1952. [CrossRef]

63. Trudeau, K.; Molina, A.; Guo, W.; Roy, S. High Glucose Disrupts Mitochondrial Morphology in Retinal Endothelial Cells. J. Pathol. 2010, 177, 447-455. [CrossRef]

64. Kim, D.; Roy, S. Effects of Diabetes on Mitochondrial Morphology and Its Implications in Diabetic Retinopathy. Investig. Ophthalmol. Vis. Sci. 2020,61, 10. [CrossRef]

65. Kowluru, R. Diabetic Retinopathy: Mitochondrial Dysfunction and Retinal Capillary Cell Death. Antioxid. Redox. Signal. 2005, 7, 1581. [CrossRef] [PubMed]

66. Barnes, D.E. DNA Damage: Air-breaks? Curr. Biol. 2002, 12, 262-264. [CrossRef]

67. Chance, B.; Sies, H.; Boveris, A. Hydroperoxide metabolism in mammalian organs. Physiol. Rev. 1979, 59, 527-603. [CrossRef] [PubMed] 
68. Karanjawala, Z.; Murphy, N.; Hinton, D.; Hsieh, C.; Lieber, M. Oxygen Metabolism Causes Chromosome Breaks and Is Associated with the Neuronal Apoptosis Observed in DNA Double-Strand Break Repair Mutants. Curr. Biol. 2002, 12, 397-402. [CrossRef]

69. Santos, J.; Tewari, S.; Kowluru, R.A. Compensatory mechanism protects retinal mitochondria from initial insult in diabetic retinopathy. Free Radic. Biol. Med. 2012, 53, 1729-1737. [CrossRef] [PubMed]

70. Madsen-Bouterse, S.; Zhong, Q.; Mohammad, G.; Ho, Y.; Kowluru, R. Oxidative damage of mitochondrial DNA in diabetes and its protection by manganese superoxide dismutase. Free Radic. Res. 2010, 44, 313-321. [CrossRef]

71. Aso, Y.; Inukai, T.; Tayama, K.; Takemura, Y. Serum concentrations of advanced glycation endproducts are associated with the development of atherosclerosis as well as diabetic microangiopathy in patients with type 2 diabetes. Acta Diabetol. 2000, 37, 87-92. [CrossRef]

72. Khangholi, S.; Majid, F.; Berwary, N.; Ahmad, F.; Aziz, R. The Mechanisms of Inhibition of Advanced Glycation End Products Formation through Polyphenols in Hyperglycemic Condition. Planta Medica 2015, 82, 32-45. [CrossRef] [PubMed]

73. Brownlee, M. The pathobiology of diabetic complications: A unifying mechanism. Diabetes 2005, 54, 1615-1625. [CrossRef]

74. Genuth, S.; Sun, W.; Cleary, P.; Gao, X.; Sell, D.R.; Lachin, J. Skin advanced glycation end products glucosepane and methylglyoxal hydroimidazolone are independently associated with long-term microvascular complication progression of type 1 diabetes. Diabetes 2015, 64, 266-278. [CrossRef]

75. Ames, B.; Shigenaga, M.; Hagen, T. Oxidants, antioxidants, and the degenerative diseases of aging. Proc. Natl. Acad. Sci. USA 1993, 90, 7915-7922. [CrossRef] [PubMed]

76. Murillo, A.; Fernandez, M. Potential of Dietary Non-Provitamin A Carotenoids in the Prevention and Treatment of Diabetic Microvascular Complications. Adv. Nutr. 2016, 7, 14-24. [CrossRef]

77. Scanlon, G.; Loughman, J.; Farrell, D.; McCartney, D. A review of the putative causal mechanisms associated with lower macular pigment in diabetes mellitus. Nutr. Res. Rev. 2019, 32, 247-264. [CrossRef] [PubMed]

78. Sasaki, M.; Ozawa, Y.; Kurihara, T.; Kubota, S.; Yuki, K.; Noda, K.; Kobayashi, S.; Ishida, S.; Tsubota, K. Neurodegenerative influence of oxidative stress in the retina of a murine model of diabetes. Diabetologia 2010, 53, 971-979. [CrossRef]

79. Wang, W.; Tam, K.C.; Ng, T.C.; Goit, R.K.; Chan, K.L.S.; Lo, A.C.Y. Long-term lutein administration attenuates retinal inflammation and functional deficits in early diabetic retinopathy using the Ins2Akita/+ mice. BMJ Open Diabetes Res. Care 2020, 8, e001519. [CrossRef] [PubMed]

80. Kamoshita, M.; Toda, E.; Osada, H.; Narimatsu, T.; Kobayashi, S.; Tsubota, K.; Ozawa, Y. Lutein acts via multiple antioxidant pathways in the photo-stressed retina. Sci. Rep. 2016, 6, 1-10. [CrossRef]

81. Li, C.; Miao, X.; Li, F.; Wang, S.; Liu, Q.; Wang, Y.; Sun, J. Oxidative stress-related mechanisms and antioxidant therapy in diabetic retinopathy. Oxid. Med. Cell. Longev. 2017, 2017, 9702820. [CrossRef]

82. Keegan, G.; Pardhan, S.; Chichger, H. Lutein and zeaxanthin attenuates VEGF-induced neovascularisation in human retinal microvascular endothelial cells through a Nox4-dependent pathway. Exp. Eye Res. 2020, 197, 108104. [CrossRef] [PubMed]

83. Hwang, J.S.; Han, S.G.; Lee, C.H.; Seo, H.G. Lutein suppresses hyperglycemia-induced premature senescence of retinal pigment epithelial cells by up-regulating SIRT1. J. Food Biochem. 2018, 42, e12495. [CrossRef]

84. Ravikrishnan, R.; Rusia, S.; Ilamurugan, G.; Salunkhe, U.; Deshpande, J.; Shankaranarayanan, J.; Shankaranarayana, M.L.; Soni, M.G. Safety assessment of lutein and zeaxanthin (Lutemax ${ }^{\mathrm{TM}}$ 2020): Subchronic toxicity and mutagenicity studies. Food Chem. Toxicol. 2011, 49, 2841-2848. [CrossRef] [PubMed]

85. Kumar, D.P.; Ravikumar, C.; Eswarappa, R.; Krishnappa, H.; Rao, K.S.; Quiroga, J.T.; Raviyadava. Sub-chronic (90 day) oral toxicity study in rats with lutein diacetate. Toxicol. Int. 2009, 16, 55-62.

86. Nidhi, B.; Baskaran, V. Acute and Subacute Toxicity Assessment of Lutein in Lutein-Deficient Mice. J. Food Sci. 2013, 78, 1636-1642. [CrossRef]

87. Ranganathan, A.; Hindupur, R.; Vallikannan, B. Biocompatible lutein-polymer-lipid nanocapsules: Acute and subacute toxicity and bioavailability in mice. Mater. Sci. Eng. C 2016, 69, 1318-1327. [CrossRef]

88. Xu, X.; Zhang, L.; Shao, B.; Sun, X.; Ho, C.; Li, S. Safety evaluation of meso-zeaxanthin. Food Control 2013, 32, 678-686. [CrossRef] 
89. Ravi, K.B.; Reddy, K.R.R.; Shankaranarayanan, J.; Deshpande, J.V.; Juturu, V.; Soni, M.G. Safety Evaluation of Zeaxanthin Concentrate (Omnixan $\left.{ }^{\mathrm{TM}}\right)$ : Acute, Subchronic Toxicity and Mutagenicity Studies. Food Chem. Toxicol. 2014, 72, 30-39. [CrossRef]

90. Thurnham, D.; Howard, A. Studies on Meso-Zeaxanthin for Potential Toxicity and Mutagenicity. Food Chem. Toxicol. 2013, 59, 455-463. [CrossRef]

91. Chew, E.Y.; Clemons, T.E.; SanGiovanni, J.P.; Danis, R.; Elman, M.; Antoszyk, A.; Ruby, A.; Orth, D.; Bressler, S.; Fish, G.; et al. Lutein + Zeaxanthin and Omega-3 Fatty Acids for Age-Related Macular Degeneration. JAMA 2013, 309, 2005. [CrossRef]

92. Akuffo, K.; Nolan, J.; Howard, A.; Moran, R.; Stack, J.; Klein, R. Sustained supplementation and monitored response with differing carotenoid formulations in early age-related macular degeneration. Eye 2015, 29, 902-912. [CrossRef] [PubMed]

93. Beatty, S.; Chakravarthy, U.; Nolan, J.; Muldrew, K.; Woodside, J.; Denny, F.; Stevenson, M.R. Secondary Outcomes in a Clinical Trial of Carotenoids with Coantioxidants versus Placebo in Early Age-related Macular Degeneration. Ophthalmology 2013, 120, 600-606. [CrossRef] [PubMed]

94. Berrow, E.; Bartlett, H.; Eperjesi, F.; Gibson, J. The effects of a lutein-based supplement on objective and subjective measures of retinal and visual function in eyes with age-related maculopathy-A randomised controlled trial. Br. J. Nutr. 2012, 109, 2008-2014. [CrossRef]

95. Bone, R.A.; Landrum, J.T. Dose-dependent response of serum lutein and macular pigment optical density to supplementation with lutein esters. Arch. Biochem. Biophys. 2010, 504, 50-55. [CrossRef]

96. Dawczynski, J.; Jentsch, S.; Schweitzer, D.; Hammer, M.; Lang, G.; Strobel, J. Long term effects of lutein, zeaxanthin and omega-3-LCPUFAs supplementation on optical density of macular pigment in AMD patients: The LUTEGA study. Graefes. Arch. Clin. Exp. Ophthalmol. 2013, 251, 2711-2723. [CrossRef]

97. Fujimura, S.; Ueda, K.; Nomura, Y.; Yanagi, Y. Preliminary analysis of the relationship between serum lutein and zeaxanthin levels and macular pigment optical density. Clin. Ophthalmol. 2016, 10, 2149-2155. [CrossRef]

98. Hammond, B.; Fletcher, L.; Roos, F.; Wittwer, J.; Schalch, W. A Double-Blind, Placebo-Controlled Study on the Effects of Lutein and Zeaxanthin on Photostress Recovery, Glare Disability, and Chromatic Contrast. Investig. Ophthalmol. Vis. Sci. 2014, 55, 8583-8589. [CrossRef]

99. Huang, Y.; Dou, H.; Huang, F.; Xu, X.; Zou, Z.; Lu, X. Changes following supplementation with lutein and zeaxanthin in retinal function in eyes with early age-related macular degeneration: A randomised, double-blind, placebo-controlled trial. Br. J. Ophthalmol. 2014, 99, 371-375. [CrossRef]

100. Stringham, J.M.; Stringham, N.T. Serum and retinal responses to three different doses of macular carotenoids over 12 weeks of supplementation. Exp. Eye Res. 2016, 151,1-8. [CrossRef]

101. Christen, W.G.; Liu, S.; Glynn, R.J.; Gaziano, J.M.; Buring, J.E. Dietary Carotenoids, Vitamins C and E, and Risk of Cataract in Women. Arch. Ophthalmol. 2008, 126, 102-109. [CrossRef] [PubMed]

102. Lyle, B.J.; Mares-Perlman, J.A.; Klein, B.E.K.; Klein, R.; Palta, M.; Bowen, P.E.; Greger, J.L. Serum carotenoids and tocopherols and incidence of age-related nuclear cataract. Am. J. Clin. Nutr. 1999, 69, 272-277. [CrossRef] [PubMed]

103. Lyle, B.J.; Mares-Perlman, J.A.; Klein, B.E.; Klein, R.; Greger, J.L. Antioxidant intake and risk of incident age-related nuclear cataracts in the Beaver Dam Eye Study. Am. J. Epidemiol. 1999, 149, 801-809. [CrossRef]

104. Brown, L.; Rimm, E.; Seddon, J.; Giovannucci, E.; Chasan-Taber, L.; Spiegelman, D.; Willett, W.C.; Hankinson, S.E. A prospective study of carotenoid intake and risk of cataract extraction in US men. Am. J. Clin. Nutr. 1999, 70, 517-524. [CrossRef]

105. Chasan-Taber, L.; Willett, W.; Seddon, J.; Stampfer, M.; Rosner, B.; Colditz, G.; Speizer, F.E.; Hankinson, S.E. A prospective study of carotenoid and vitamin A intakes and risk of cataract extraction in US women. Am. J. Clin. Nutr. 1999, 70, 509-516. [CrossRef]

106. Glaser, T.; Doss, L.; Shih, G.; Nigam, D.; Sperduto, R.; Ferris, F.; Agron, E.; Clemons, T.E.; Chew, E.Y. The Association of Dietary Lutein plus Zeaxanthin and B Vitamins with Cataracts in the Age-Related Eye Disease Study. Ophthalmology 2015, 122, 1471-1479. [CrossRef]

107. Age-Related Eye Disease Study Research Group. A randomized, placebo-controlled, clinical trial of high-dose supplementation with vitamins $\mathrm{C}$ and $\mathrm{E}$ and beta carotene for age-related cataract and vision loss: AREDS report no. 9. Arch. Ophthalmol. 2001, 119, 1439-1452. [CrossRef] 
108. Papudesu, C.; Clemons, T.E.; Agrón, E.; Chew, E.Y. Age-Related Eye Disease Study 2 Research Group, Association of Mortality with Ocular Diseases and Visual Impairment in the Age-Related Eye Disease Study 2: Age-Related Eye Disease Study 2 Report Number 13. Ophthalmology 2018, 125, 512-521. [CrossRef]

109. Christen, W.G.; Manson, J.E.; Glynn, R.J.; Gaziano, J.M.; Sperduto, R.D.; Buring, J.E.; Hennekens, C.H. A Randomized Trial of Beta Carotene and Age-Related Cataract in US Physicians. Arch. Ophthalmol. 2003, 121, 372-378. [CrossRef] [PubMed]

110. Christen, W.; Glynn, R.; Sperduto, R.; Chew, E.; Buring, J. Age-related cataract in a randomized trial of beta-carotene in women. Ophthalmic Epidemiol. 2004, 11, 401-412. [CrossRef]

111. Chylack, L.T.; Brown, N.P.; Bron, A.; Hurst, M.; Köpcke, W.; Thien, U.; Schalch, W. The Roche European American Cataract Trial (REACT): A randomized clinical trial to investigate the efficacy of an oral antioxidant micronutrient mixture to slow progression of age-related cataract. Ophthalmic Epidemiol. 2002, 9, 49-80. [CrossRef]

112. Teikari, J.M.; Virtamo, J.; Rautalahti, M.; Palmgren, J.; Liesto, K.; Heinonen, O.P. Long-term supplementation with alpha-tocopherol and beta-carotene and age-related cataract. Acta Ophthalmol. Scand. 1997, 75, 634-640. [CrossRef]

113. Azar, G.; Maftouhi, M.Q.; Masella, J.J.; Mauget-Faÿsse, M. Macular pigment density variation after supplementation of lutein and zeaxanthin using the Visucam ®200 pigment module: Impact of age-related macular degeneration and lens status. J. Fr. Ophtalmol. 2017, 40, 303-313. [CrossRef] [PubMed]

114. Olmedilla, B.; Granado, F.; Blanco, I.; Vaquero, M. Lutein, but not alpha-tocopherol, supplementation improves visual function in patients with age-related cataracts: A 2-y double-blind, placebo-controlled pilot study. Nutrition 2003, 19, 21-24. [CrossRef]

115. Korobelnik, J.; Rougier, M.; Delyfer, M.; Bron, A.; Merle, B.M.J.; Savel, H.; Chene, G.; Delcourt, C.; Creuzot-Garcher, C. Effect of Dietary Supplementation With Lutein, Zeaxanthin, and $\omega-3$ on Macular Pigment: A Randomized Clinical Trial. JAMA Ophthalmol. 2017, 135, 1259-1266. [CrossRef]

116. Bahrami, H.; Melia, M.; Dagnelie, G. Lutein supplementation in retinitis pigmentosa: PC-based vision assessment in a randomized double-masked placebo-controlled clinical trial [NCT00029289]. BMC Ophthalmol. 2006, 6, 23. [CrossRef] [PubMed]

117. Shao, A.; Hathcock, J.N. Risk assessment for the carotenoids lutein and lycopene. Regul. Toxicol. Pharm. 2006, 45, 289-298. [CrossRef]

118. Celentano, J.C.; Burke, J.D.; Hammond, B.R., Jr. In Vivo Assessment of Retinal Carotenoids: Macular Pigment Detection Techniques and Their Impact on Monitoring Pigment Status. J. Nutr. 2002, 132, 535-539. [CrossRef]

119. Wu, J.; Cho, E.; Willett, W.C.; Sastry, S.M.; Schaumberg, D.A. Intakes of Lutein, Zeaxanthin, and Other Carotenoids and Age-Related Macular Degeneration During 2 Decades of Prospective Follow-up. JAMA Ophthalmol. 2015, 133, 1415. [CrossRef]

120. Eisenhauer, B.; Natoli, S.; Liew, G.; Flood, V. Lutein and Zeaxanthin-Food Sources, Bioavailability and Dietary Variety in Age-Related Macular Degeneration Protection. Nutrients 2017, 9, 120. [CrossRef]

121. Green-Gomez, M.; Prado-Cabrero, A.; Moran, R.; Power, T.; Gómez-Mascaraque, L.G.; Stack, J.; Nolan, J.M. The Impact of Formulation on Lutein, Zeaxanthin, and meso-Zeaxanthin Bioavailability: A Randomised Double-Blind Placebo-Controlled Study. Antioxidants 2020, 9, 767. [CrossRef] [PubMed]

Publisher's Note: MDPI stays neutral with regard to jurisdictional claims in published maps and institutional affiliations.

(C) 2020 by the authors. Licensee MDPI, Basel, Switzerland. This article is an open access article distributed under the terms and conditions of the Creative Commons Attribution (CC BY) license (http://creativecommons.org/licenses/by/4.0/). 